\title{
Ni bonded TiC cermet pyramidal lattice structures
}

\author{
Liang Dong ${ }^{*}$, Sean Agnew, and Haydn Wadley \\ Department of Materials Science and Engineering, \\ University of Virginia, Charlottesville, Virginia 22904
}

\begin{abstract}
Ultralight pyramidal lattice structures with a relative density $(\bar{\rho})$ ranging from 1.5 to $21 \%$ have been fabricated from a $\mathrm{Ni}$ bonded $\mathrm{TiC}$ cermet and configured as sandwich panels using a mechanical snap-fit and vacuum brazing technique. The lattice structures moduli and strengths have been measured using unit cell samples during out of plane compression as a function of the lattice relative density. Two strut failure modes were observed: Euler buckling of the struts dominated the response at low density, $\bar{\rho} \leq 1.5 \%$, while compressive yielding failure governed the response for $\bar{\rho}>1.5 \%$. The measurements are shown to be well predicted by micromechanics models of these strut failure modes, and excellent agreement was achieved between experimental results and finite element predictions. When compared with other cellular lattices and topologies, snap-fit $\mathrm{Ni}$ bonded $\mathrm{TiC}$ composite pyramidal lattice structures are found to exhibit superior mechanical properties, and appear to be promising candidates for high temperature applications.
\end{abstract}

\section{Introduction}

Sandwich panel structures are widely used as light structures for the efficient support of elastic bending loads $[1,2,3]$. In these applications, light, stiff face sheets are separated by a lowdensity (frequently cellular structure) core that preserves the face sheet separation during loading, thereby enabling minimization of the panel's elastic deflection. If the panel geometry is fixed, the elastic moduli of the core governs the panel's response under elastic loading. The compressive elastic moduli of a variety of cellular core materials are compared with other engineering materials in the Ashby chart shown in Figure 1(a). The highest specific modulus core material that could be made is limited by the Voigt bound for diamond (regions exceeding this are shown in grey). At densities below $1000 \mathrm{kgm}^{-3}$, the best cores are cellular (pyramidal, tetrahedral and honeycomb) lattice structures made from high specific stiffness materials such as aluminum [4,5,6] and titanium alloys [7,8,9] or carbon fiber reinforced polymer (CFRP) composites $[10,11,12,13,14]$.

\footnotetext{
*Corresponding author. Tel.: +1 434982 5678; Email address: 1d5fy@ virginia.edu
} 
The use of sandwich panels for mitigating the effects of localized, high intensity impulsive loads has begun to attract significant interest [15,16,17,18,19,20,21,22,23,24]. Sandwich structures intended for these applications are optimized by the use of high specific strength face sheet materials and combinations of core design and material that maximize core strength and in-plane stretch resistance [25]. For edge clamped panels, the best stretch and crushing-resistant core has a square honeycomb topology $[15,16,26]$. Light structures with this topology have been fabricated from carbon fiber reinforced polymer composites $[10,11,12]$, and attained core compression strengths in the $50 \mathrm{MPa}$ range at a density of about $200 \mathrm{kgm}^{-3}$, Figure 1(b). While titanium matrix composite (TMC) cores consisting of collinearly stacked and diffusion bonded titanium coated $\mathrm{SiC}$ fibers have exhibited significantly higher compressive strengths (210MPa at $700 \mathrm{kgm}^{-3}$ ), they have highly anisotropic in-plane properties [27], and are best suited for use in 2D beams. Pyramidal lattices made from high specific strength materials exhibit a strength comparable to that of square honeycombs of similar relative density, but their in-plane stretch resistance is controlled by that of the face sheets to which they are bonded [28].

Since the strength of isotropic cellular materials is limited by the Hashin-Shtrikman upper bound for a composite material [29], their compressive strength can at best scale linearly with relative density (material volume fraction) and the strength of the material from which it is made. While diamond, $\mathrm{B}_{4} \mathrm{C}, \mathrm{SiC}$ and other hard ceramics such as $\mathrm{TiC}$, and $\mathrm{TiB}_{2}$, have a hardness in the range of 20-40 GPa, their fracture toughness is very low [30,31]. Consequently, a cellular material made from such a material is likely to be too brittle for most applications. However, by using a ductile metal such as $\mathrm{Ni}$ to bind $\mathrm{TiC}$ particles, cemented carbides (also known as cermets or hard metals) with very high particle volume fractions have been made [32]. They typically combine a high modulus ( $380 \mathrm{GPa}$ ) with high strength (of 2-4 GPa) with a significant fracture toughness (approaching $20 \mathrm{MPam}^{1 / 2}$ ) [33,34]. Metal bonded TiC (or other high hardness ceramics such as $\mathrm{TiB}_{2}$ and $\mathrm{B}_{4} \mathrm{C}$ ) composites might therefore enable significant improvements in the compressive strength of a cellular material with reduced susceptibility to the defect controlled brittle behavior compared to pure ceramic approaches [35].

Nickel bonded TiC composites typically contain a nickel volume fraction of about 10-15 vol\% resulting in materials with a density of $5500 \mathrm{kgm}^{-3}$ and compressive strength of $\sim 3 \mathrm{GPa}$ [36]. Molybdenum is often added to increase the interfacial strength between the particles and metal binder [37]. Their specific strength at quasi-static loading rates is therefore very high. Their high ballistic penetration resistance accompanied by reduced radial cracking suggests that their dynamic strength and fracture toughness are also high [38]. While nickel bonded TiC composites appear to be well suited for making high specific strength cellular structures, no method to date has been developed for making them, and the mechanical response of such structures is therefore not known.

Here, we investigate the application of a simple "snap-fit" method [11] for fabricating truss structures from a Ni bonded $\mathrm{TiC}$ cermet, and combine it with a vacuum brazing technique to fabricate pyramidal lattice unit cell and sandwich structures. The quasi-static mechanical 
response of the $\mathrm{Ni}$ bonded $\mathrm{TiC}$ cermet pyramidal lattices under through thickness compression is experimentally investigated, and the compressive strengths and moduli determined as a function of lattice relative density. These results are compared with micromechanical (analytical) and finite element analysis to determine the inter relationships between lattice topology, material properties and relative density.

\section{Lattice fabrication, relative density and solid material properties}

\subsection{Ni bonded TiC cermet material characterization}

The lattices were assembled from DDG-X grade (supplied by Davis Defense Group, Fredericksburg, VA) Ni bonded TiC in the form of approximately $150 \mathrm{~mm} \times 150 \mathrm{~mm}$ plates with a nominal thickness of $10 \mathrm{~mm}$. The plates had a surface appearance and microstructure consistent with processing via self-propagating high-temperature synthesis (SHS) [39]. In this inexpensive processing approach, a green compact of the titanium and carbon powders are blended with nickel and molybdenum powders, and then exothermically reacted. The $\mathrm{Ti}+\mathrm{C} \rightarrow$ $\mathrm{TiC}$ reaction is highly exothermic with a high heat of formation of $-185 \mathrm{~kJ} / \mathrm{mol}$ for the formation of $\mathrm{TiC}$ from its elements [40]. When compared to the specific heat (room temperature) of the compact (450 500 J/kg $\mathrm{K}$, i.e., about $27 \sim 30 \mathrm{~J} / \mathrm{mol} \cdot \mathrm{K})$, it is clear the initiation of the reaction in a small region of the compacted powders rapidly heats the powder to a temperature above the melting point (the melting temperature of $\mathrm{Ni}$ and $\mathrm{TiC}$ is $1455^{\circ} \mathrm{C}$ and $3160^{\circ} \mathrm{C}$, respectively; the adiabatic combustion temperature is about $2500^{\circ} \mathrm{C}$ [37]). This locally molten region then advances through the sample, and upon cooling, $\mathrm{Ti}_{1-\mathrm{x}} \mathrm{Mo}_{\mathrm{x}} \mathrm{C}$ then precipitates from the melt.

Even when conducted in conjunction with an applied pressure, porosity remains an issue after such self-propagating high temperature synthesis (SHS) [37,41,42]. The typical pore volume fraction in this plate material was 1-5\% [33]. It was typically present as large (several hundred micron diameter) regions devoid of the metal binder. Another feature of the SHS microstructure is a relatively high level of $\mathrm{TiC}$ particle contiguity $(\sim 40 \%)$, where the ceramic particles touch one another rather than being fully isolated by metal binder. In addition, the large mismatch in coefficients of thermal expansion of ceramic and binder metal leads to significant internal residual stress [33]. These structural features of the material lead to substantial variability in the transverse rupture strength properties [34,35]. The as-received tiles were subjected to containerless hot-isostatic pressing (HIP) with the intent of reducing some of the porosity. The HIP temperature cycle involved heating to $1250^{\circ} \mathrm{C}$ under $100 \mathrm{MPa}$ hydrostatic pressure for $2 \mathrm{~h}$, followed by slow cooling at $15^{\circ} \mathrm{C} / \mathrm{min}$. The HIP treated cermet tiles were then stress-relieved by heating in vacuum at $900{ }^{\circ} \mathrm{C}$ for $30 \mathrm{~min}$ followed by cooling at a rate of $5^{\circ} \mathrm{C} / \mathrm{min}$. An Xradia (Pleasanton, CA) model micro X-ray computed tomography ( $\mu \mathrm{XCT}-200$ ) instrument was used to observe the porosity distribution in the HIP condition cermet material. The post-HIP treated material had a density of $5,496 \mathrm{~kg} / \mathrm{m}^{3}$, and $\mu \mathrm{XCT}$ revealed the sampled 
region to have a porosity level of about 1.4 vol\%, Figure 2 . Unfortunately, the HIP treatment was unable to reduce the porosity sufficiently to significantly alter the mechanical properties [34].

The microstructure of the post-treated (HIP + stress relieved) Ni bonded TiC cermet is shown in the backscatter secondary electron (BSE) scanning electron microscope image, Fig. 3. A core-rim structure [37,43] was observed in the carbides. The core tends to exhibit darker contrast than the rim, indicative of a lower concentration of high atomic number elements (i.e., less Mo, which has significant solubility in $\mathrm{TiC}$ where it substitutes on the Ti sub-lattice). Image analysis revealed that the average volume fractions of the carbide and metal binder phases were about 0.885 and 0.115 , respectively, consistent with X-ray diffraction-based measurements of phase fractions [33]. The average carbide particle diameter was about $10 \mu \mathrm{m}$.

In order to predict lattice mechanical responses, the compressive strength, flexural strength and elastic stiffness of the HIP and stress relieved $\mathrm{Ni}$ bonded $\mathrm{TiC}$ cermet were measured. A representative compressive stress versus strain response measured at a strain rate of $10^{-4} \mathrm{~s}^{-1}$ is shown in Fig. 4. The elastic stiffness and compressive strength were determined to be $359 \mathrm{GPa}$, and $2778 \mathrm{MPa}$, respectively. Four points bending tests of samples in this condition gave an average flexural strength of $568 \mathrm{MPa}$. Table 1 summarizes the mechanical properties of the Ni bonded TiC cermet.

\subsection{Lattice fabrication}

Pyramidal unit cells and sandwich panels with a pyramidal lattice structure core were fabricated from the Ni bonded $\mathrm{TiC}$ cermet plates using a snap-fit method [11]. Truss patterns, Fig. 5 (a) were wire EDM cut from the middle section of the post-treated tile. These patterns were then snap-fitted into each other to produce a pyramidal truss. The pyramidal truss nodes were sunk-fitted into $3.175 \mathrm{~mm}$ thick cermet face sheets containing EDM cut grooves with a depth of 1.6 mm. A Ni-11wt.\%P braze alloy (Hi-Temp ${ }^{\circledR}$ 932, Lucas-Milhaupt Inc., Cudahy, WI) was applied to the nodal regions of the assembled structure. This braze alloy has a solidus temperature of $877^{\circ} \mathrm{C}$. Brazing was accomplished by placing the lattice structures in a hightemperature vacuum brazing furnace and heating at $5{ }^{\circ} \mathrm{C} / \mathrm{min}$ to $500{ }^{\circ} \mathrm{C}$, holding for 15 min (to volatilize the polymer binder), and then heating to $1060{ }^{\circ} \mathrm{C}$ for $20 \mathrm{~min}$ at a chamber pressure of $\sim 10^{-4}$ Torr. $^{\dagger}$ After brazing, the furnace was cooled at a rate of $5^{\circ} \mathrm{C} / \mathrm{min}$ to ambient temperature. Fig. 6 shows the fabricated cermet pyramidal unit cell samples after brazing.

\subsection{Relative Density}

\footnotetext{
$\dagger$ These conditions were a carefully chosen compromise. At the temperature used here, the braze alloy wetted the cermet well, and was drawn into the narrow gaps between the truss members. However, due to the high viscosity of this Ni-P braze alloy, not all the gaps between trusses were fully filled during brazing. Use of a higher brazing temperature improved the flowability of the braze, but resulted in cermet erosion (dissolution of the cermet in the braze alloy).
} 
A schematic drawing of the snap-fit pyramidal unit cell lattice is shown in Fig. 5(c), together with a coordinate system. Note that the struts had a square cross section truss, $t=w$, and a truss inclination angle $\omega=45^{\circ}$ was selected to balance the compressive and shear responses of the structure. By calculating the volumes of regions occupied by material, and scaling this by the unit cell volume, the relative density, $\bar{\rho}$ of the pyramidal unit cell (including nodal mass contributions) is given by [11];

$$
\bar{\rho}=\frac{2 l t w+h t(b+c-t)}{(l \sin \omega+h)\left(l \cos \omega+\frac{1}{2}(b+c)\right)^{2}}
$$

where the geometric parameters are defined in Fig. 5 (b and c). At vanishing node volume, Eq. 1 reduces to

$$
\bar{\rho}=\frac{2 t w}{l^{2} \cos ^{2} \omega \sin \omega}
$$

The extra volume of material at the nodes was intended to reduce stress concentrations and prevent node failure occurring prior to truss failure.

\subsection{Braze microstructure}

Energy dispersive X-ray analysis was used to obtain elemental distribution maps at a typical nodal braze joint with a $75 \mu \mathrm{m}$ thick braze filled gap are shown in Fig. 7. The maps show the spatial distribution of the base material elements $(\mathrm{Ni}, \mathrm{Mo}, \mathrm{Ti}, \mathrm{C})$ and those of the braze alloy $(\mathrm{Ni}, \mathrm{P})$ in and around the braze joint. The Ni-11wt\%P eutectic alloy had decomposed into Ni and $\mathrm{Ni}_{3} \mathrm{P}$ (the regions with substantial $\mathrm{P}$ ) using the brazing recipe followed here. This was accompanied by transverse diffusion of $\mathrm{P}$ a distance of $\sim 200 \mu \mathrm{m}$ into the cermet base material.

\section{Compression responses}

\subsection{Methodology}

The cermet pyramidal unit cell samples were tested at ambient temperature in the $z$ (through-thickness) direction in compression at a nominal strain rate of $3 \times 10^{-4} \mathrm{~s}^{-1}$ in accordance with ASTM standard C365. A laser extensometer enabled measurement of the compressive strain by monitoring the displacements of the face sheets. Unload-reload cycles were conducted prior to the onset of inelastic responses in order to determine the elastic stiffness of the specimens. A model v1610 Phantom high-speed camera (Wayne, NJ) recorded an oblique view of the pyramidal unit cell samples to observe the failure mechanisms of the pyramidal trusses. The camera was set to an exposure time of $19 \mu \mathrm{s}$ with an inter-frame delay of $20 \mu \mathrm{s}$, which resulted in an image resolution of $128 \times 64$ pixels. 
In-situ digital image correlation (DIC) was also set-up to determine three-dimensional strain maps during deformation of the pyramidal unit cell samples. The DIC system tracked the displacement of a speckle pattern formed by first spray painting the X-Y surfaces (normal to the loading direction) white followed by the application of a stochastic pattern of $0.1 \mathrm{~mm}$ diameter black dots that covered approximately 50\% of the surface area. A pair of 5 megapixel CCD cameras was positioned in a stereo configuration to capture the speckle pattern coated surfaces. The images were analyzed using the Aramis v.6.3 (GOM mbH; Braunschweig, Germany) 3D image correlation software.

\subsection{Compression results}

The compressive stress-strain responses of the pyramidal unit cell samples are shown in Fig. 8 (solid curves). In all cases, an initial linear response was observed followed by a region of nonlinear response. Typically, the peak stress was attained as subcritical strut failure was first observed. The stress then decreased rapidly with increasing strain, with serrations on the stressstrain curve associated with a series of strut failures, indicative of slightly different strut compressive strengths. The measured moduli and strengths are summarized in Table 4. High speed video images of a pyramidal unit cell sample $(\bar{\rho}=8.2 \%)$ showing the failure mode in compression are presented in Fig. 9. The times $t_{0}$ and $t_{1}$ refer to the time points marked on the stress-strain curve of the $\bar{\rho}=8.2 \%$ sample shown in Fig. 8. Fig. 10 schematically illustrates the failure mechanism of a pyramidal truss in $2 \mathrm{D}$ and $3 \mathrm{D}$ perspective. Fracture initiated in strut 1 near the two ends of a strut. These then grew and linked up to result in a diagonal fracture of the strut. Struts 2, 3, and 4 subsequently failed by shear facture near the ends due to transient forces that developed in the system as the loads supported by now missing strut 1 were redistributed. No node-associated failure was observed for any of the samples tested here. A representative truss fracture surface is shown in Fig. 11(a), and a representative fracture topology of the snapfitted node after lattice compression failure is shown in Fig. 11(b).

Fig. 12 shows the truss surfaces of a pyramidal unit cell sample with $\bar{\rho}=8.2 \%$ just prior to reaching its peak stress. A false color rendering of the DIC determined von Mises strain is overlaid on the image. The von Mises strain is widely used as a criterion for yielding, and is defined as [44];

$$
\varepsilon_{v}=\frac{\sqrt{2}}{3}\left[\left(\varepsilon_{1}-\varepsilon_{2}\right)^{2}+\left(\varepsilon_{2}-\varepsilon_{3}\right)^{2}+\left(\varepsilon_{3}-\varepsilon_{1}\right)^{2}\right]^{1 / 2}
$$

where $\varepsilon_{1}, \varepsilon_{2}$ and $\varepsilon_{3}$ are principal strains. The maximum measured von Mises strains were observed near the two ends of each pyramidal strut where fracture initiated.

\subsection{Mechanical responses of multi-cell pyramidal lattice}


To assess the validity of the single unit cell measurements, sandwich panels with a multiple pyramidal unit cell $(2 \times 3)$ core were made and tested using similar testing procedures to those of the single unit cell tests. Figure 13 shows the assembly and a fully assembled multi-cell pyramidal lattice core with a relative density of $8.2 \%$. Its compressive stress strain responses are shown in Fig. 14(a), and compared with unit cell counterpart behavior and FEM predictions, and are summarized in Table 5. High speed video images of the multi-cell pyramidal lattice $(\bar{\rho}=8.2 \%)$ showing its characteristic failure modes in compression are shown in Fig. 14(b). Again, $t_{0}$ and $t_{1}$ refer to the time points marked on the stress-strain curve shown in Fig. 14(a). Fracture initiated in a subset of struts and their failure mode was identical to that observed in unit cell lattice (Fig. 9). No node associated failure was observed for any of the samples tested here.

\section{Finite element analysis}

Finite element analysis techniques were used to investigate the failure mechanisms responsible for the observed mechanical responses of the $\mathrm{Ni}$ bonded $\mathrm{TiC}$ pyramidal cellular structures. All simulations were performed with the implicit solver of the commercially available finite element software Abaqus Standard (version 6.13). The geometry and relative density of the modeled pyramidal unit cells were identical to those reported in Tables 2 and 3. Material properties were extracted from the experimental compressive stress-strain response of the HIP and stress relief-treated $\mathrm{Ni}$ bonded TiC cermet. To bound the responses, compressive strengths of $2600 \mathrm{MPa}$ and $3300 \mathrm{MPa}$ for the parent material were used. The built-in ductile damage model of ABAQUS was used to identify failure of the truss members. The damage initiation and evolution were based on the equivalent fracture strain and fracture energy [45] and a Hillerborg fracture energy $G_{f}$ of $1.1 \times 10^{3} \mathrm{~N} / \mathrm{m}$ (obtained from fracture toughness $K_{1 \mathrm{c}}$ tests [34]) were used for the material model. The FE models were constructed using three-dimensional hexahedral elements (C3D8R in Abaqus notation) with at least 11 elements through the truss thickness. Further mesh refinements did not improve the accuracy of the predictions significantly. Two rigid faces were added to represent the face sheets. A surface-based tie constraint was applied on the interfaces between the pyramidal core and the rigid faces. The bottom (rigid) face was clamped against translational and rotational displacements. No lateral motion (in the $x$ and $y$ directions) or rotation of the top face were allowed. When the pyramidal unit cell lattice was compressed by a downward displacement $\delta$, an axial force with vertical component $P$ developed in each truss of the lattice. The compressive stress was then calculated as $\sigma=4 P / A$, and the stiffness as $E=4 P H / A \delta$, where $A$ and $H$ represent the cross sectional area of the base and the height of the pyramidal unit cell.

Numerical results of the stress-strain diagrams of designed pyramidal lattices are compared with experimental measurements in Fig. 8. Two simulated responses are shown using the bounding values (2600 MPa minimum and $3300 \mathrm{MPa}$ maximum) for the compressive strength of the parent material. Good agreement was achieved between the FE model predictions 
and measurements. Numerical results of the compressive moduli and strengths are listed in Table 4. It is noted here that the simulated moduli are significant higher than those measured. This discrepancy is frequently seen in tests of cellular materials, and has been attributed to small differences in strut geometry resulting in non-uniform loading of the struts $[4,6,46,47]$.

Fig. 15 shows a von Mises stress map [48] of a deformed pyramidal unit cell lattice with $\bar{\rho}=8.2 \%$ at various compressive strains. This stress is defined as

$$
\sigma_{v}=\frac{1}{\sqrt{2}}\left[\left(\sigma_{1}-\sigma_{2}\right)^{2}+\left(\sigma_{2}-\sigma_{3}\right)^{2}+\left(\sigma_{3}-\sigma_{1}\right)^{2}\right]^{1 / 2}
$$

where $\sigma_{1}, \sigma_{2}$ and $\sigma_{3}$ are principal stresses. The maximum von Mises stress (location of first yielding) occurred near the two ends of each pyramidal strut and subsequently expanded to form a high stress band along the strut diagonal line. Such a von Mises stress map implies that failure initiates near the two ends of the strut and then propagates along the strut diagonal line; an implication that agreed well with the experimental high speed video and DIC observations.

\section{Discussion}

\subsection{Comparison of predictions with measurements}

The measured compressive moduli as a function of the relative density of the snap-fit pyramidal unit cell samples are shown in Fig. 16(a). Analytical (see Appendix for their calculation) and numerical predictions are also plotted on the figure. A solid cermet material elastic stiffness of $360 \mathrm{GPa}$ was used for the model predictions. The experimental measurements

are found to be well predicted by these model estimates. The numerical results show predictions using free rotation $(k=1)$ and built-in $(k=2)$ estimates for the truss end conditions. The experiments lie between the $k=1$ and 2 model predictions which suggests that the rotational stiffness $k$ lies between these struts end conditions.

The experimental compressive strength data as a function of the relative density are shown in Fig. 16(b). The measurements are compared with both the analytical and numerical FEM predictions. The FE model used either $\sigma_{c}=2600 \mathrm{MPa}$ or $3300 \mathrm{MPa}$ to predict the lower and upper bounds of the pyramidal lattice compressive strengths. A conservative compressive strength of $\sigma_{c}=2600 \mathrm{MPa}$ was used for the analytical model predictions. The measurements are in good agreement with the analytical model predictions: at low relative density $(\bar{\rho}<0.03)$, the measurements follow the elastic buckling model prediction. The measurements then become consistent with the yielding model when $\bar{\rho}>0.03$ indicating a transition in mechanism as the relative density was increased. The FEM results are in excellent agreement with the experimental measurements. The numerical predictions, with the $\sigma_{c}=2600 \mathrm{MPa}$ material model, lie between the $k=1$ and 2 analytical predictions; this is consistent with the assumption that the rotational 
stiffness $k$ lies between 1 and 2 for the actual struts end conditions. The results demonstrate that the material struts fail in a near uniaxial compressive state of stress, which is significant, because the strength in bending of this material is lower by nearly a factor of 5 [34]. By designing the stress state to remain nearly compressive within the struts enables the structure to take full advantage of the best mechanical attributes of the material, while avoiding its deficiencies.

\subsection{Comparisons with competing materials}

The measured compressive moduli and strengths of the snap-fit Ni bonded TiC cermet pyramidal lattices investigated here are included in the material property charts of Fig. 1. The compressive moduli of the snap-fit Ni bonded $\mathrm{TiC}$ cermet pyramidal lattices, Fig 1(a), are significantly superior to foamed structures and clearly superior to lattice structures made from CFRP [11,49], Ti [7,8,46] and Al alloys [5,6], and comparable to the TMC collinear lattices [27]. They are comparable to the stiffness of CFRP honeycombs of similar density.

The strength of the Ni bonded $\mathrm{TiC}$ cermet pyramidal lattices loaded in compression, Fig 1(b), are inferior to the CFRP counterparts for densities lower than $0.2 \mathrm{Mg} / \mathrm{m}^{3}$ where the elastic buckling failure mechanism of the solid struts is dominant. However, at higher densities where elastic buckling is not responsible for the compressive strength, the $\mathrm{Ni}$ bonded $\mathrm{TiC}$ lattices dominate all other lattices except the highest density titanium matrix composite system.

The Ni bonded $\mathrm{TiC}$ cermet pyramidal lattices investigated here are expected to retain good dimensional stability during loading at temperature even up to $900^{\circ} \mathrm{C}$ [50], and may therefore provide new opportunities from high temperature sandwich panel and thermal management applications.

\section{Conclusions}

1. Ni bonded TiC cermet pyramidal lattices with relative densities in the range $1.5-21 \%$ have been manufactured via a snap-fit and vacuum brazing approach.

2. The elastic moduli and strengths of the lattice structures have been measured under throughthickness compression as a function of the snap-fit structure relative density.

3. The moduli (1.4-21GPa) and strengths (10.4-247MPa) of the manufactured pyramidal lattice structures are well predicted by micromechanics modeling and finite element analysis.

4. The Ni bonded $\mathrm{TiC}$ cermet pyramidal lattices exhibit excellent mechanical properties superior to existing materials and topologies. 


\section{Acknowledgements}

We are grateful to the Office of Naval Research (program Manager Dr. David Shifler) for support of this work under ONR Grant number N00014-11-1-0919.

\section{Appendix}

\section{Analytical model for compressive response}

\section{Compressive stiffness}

Consider an edge clamped out-of-plane strut (i.e., rotational stiffness $k=2$ ) of the octahedral cell with length $l$ and square cross section of side length $t$ as shown in Fig. A1(a). The corresponding free body diagram of such a strut is shown in Fig. A1(b). With an imposed displacement at one end along $z$ direction denoted as $\delta_{z z}$, the axial force $F_{A}$ and shear force $F_{S}$ in the strut are given by elementary beam theory

$$
\begin{aligned}
& F_{A}=E_{S} t^{2} \frac{\delta_{z z} \sin \omega}{l} \\
& F_{S}=\frac{12 E_{S} I \delta_{z z} \cos \omega}{l^{3}}
\end{aligned}
$$

where $E_{s}$ is the Young's modulus of the solid material, $\omega$ is strut inclined angle $\left(=45^{\circ}\right), I$ is the second moment of area of the strut cross section given by $I=t^{4} / 12$ for square cross section of side length $t$. The total applied force, $F_{\text {strut }}$, on such a single strut in the $z$ direction follows as

$$
F_{\text {strut }}=F_{\mathrm{A}} \sin \omega+F_{\mathrm{S}} \cos \omega=\frac{E_{S} \delta_{z z}}{2 l} t^{2}\left[1+\left(\frac{t}{l}\right)^{2}\right]
$$

Now consider the unit cell sketched in Fig. A1(a). The total force, $F$, applied on the unit cell in the $z$ direction is equal to $4 F_{\text {strut }}$; stress, $\sigma_{z z}$ and strain, $\varepsilon_{z z}$ applied to the unit cell are related to the force $F$ and displacement $\delta_{z z}$ via;

$$
\sigma_{z z}=\frac{F}{A}=\frac{2 E_{S} \delta_{z z}}{l A} t^{2}\left[1+\left(\frac{t}{l}\right)^{2}\right]
$$

and

$$
\varepsilon_{z z}=\frac{\delta_{z z}}{H}
$$

where $H$ is the unit cell height $(H=l \sin \omega+h), A$ is cross-sectional area $\left(A=\left(\frac{2 l \cos \omega+b+c}{\sqrt{2}}\right)^{2}\right)$, as shown in Fig. A1(a). The effective Young's modulus $E_{z z}$ of the unit cell is then given by; 


$$
E_{z z}=\frac{\sigma_{z z}}{\varepsilon_{z z}}=\frac{2 E_{s} t^{2} H}{l A}\left[1+\left(\frac{t}{l}\right)^{2}\right]
$$

Eq. A3 and A5 apply for fixed-end (built-in) struts $(k=2)$. The first and second terms in Eq.A3 and A5 represent the contributions to the stiffness of the pyramidal core due to the stretching and bending of the struts, respectively; for pin-joined struts $(k=1)$, the contribution to the stiffness due to bending of the struts is negligible (i.e., the second term of Eq. A3 and A5), Eq. A3 and A5 reduce to,

$$
E_{z z}=\frac{\sigma_{z z}}{\varepsilon_{z z}}=\frac{2 E_{s} t^{2} H}{l A}
$$

and

$$
\sigma_{z z}=\frac{F}{A}=\frac{2 E_{S} \delta_{z z}}{l A} t^{2}
$$

\section{Compressive strength}

With $k=1$ pin-joint condition, Eq. A7 gives the compressive stress $\sigma_{z z}$ applied to the pyramidal unit cell in the $\mathrm{z}$ direction; the corresponding axial stress $\sigma_{\mathrm{A}}$ in a pyramidal strut is given by

$$
\sigma_{A}=\frac{E_{s} \delta_{z z}}{\sqrt{2} l}
$$

Therefore, the stress applied to the pyramidal unit cell, $\sigma_{z z}$, can be expressed in terms of the axial stress, $\sigma_{A}$, in a pyramidal strut;

$$
\sigma_{z z}=\frac{2 \sqrt{2} \sigma_{A} t^{2}}{A}
$$

The pyramidal strut can support load until its collapse strength $\sigma_{\mathrm{c}}$ is achieved. Therefore, the lattice peak strength is given by

$$
\sigma_{z z}^{p k}=\frac{2 \sqrt{2} \sigma_{c} t^{2}}{A}
$$

At high relative densities, $l$ tends towards $t$, and a lattice will fail by yielding of the low aspect ratio struts. At low densities, struts are slender enough to collapse by elastic buckling $(k=$ 1) prior to compressive plastic yielding at a stress given by

$$
\sigma_{\mathrm{E}}=\frac{k^{2} \pi^{2} E_{\mathrm{S}}}{12}\left(\frac{t}{l}\right)^{2}=\frac{\pi^{2} E_{\mathrm{s}}}{12}\left(\frac{t}{l}\right)^{2}
$$


Therefore, the lattice peak strength due to strut elastic buckling is given by

$$
\sigma_{z z}^{p k}=\frac{\sqrt{2} \pi^{2} E_{\mathrm{s}} t^{2}}{6 A}\left(\frac{t}{l}\right)^{2}
$$

With $k=2$ clamped end condition, Eq. A3 gives the compressive stress;

$$
\sigma_{z z}=\frac{2 \sqrt{2} \sigma_{A} t^{2}}{A}\left[1+\left(\frac{t}{l}\right)^{2}\right]
$$

However, in the $k=2$ case, $\sigma_{\mathrm{A}}$ cannot equal to the collapse strength $\sigma_{\mathrm{c}}$ as bending of the strut introduced extra normal stress (tension on one side of the neutral axis and compression on the other side) in the beam cross-section; the pyramidal strut can support load until the following criterion is achieved in the dangerous section;

$$
\sigma_{A}+\sigma_{b}=\sigma_{A}+\frac{M(t / 2)}{t^{4} / 12}=\sigma_{\mathrm{c}}
$$

where $M$ is the maximum bending moment, and is given by

$$
M=\frac{F_{s} l}{2}=\frac{\sigma_{A} t^{4}}{2 l}
$$

Substituting Eq. A15 into Eq. A14 yields

$$
\sigma_{A}\left(1+\frac{3 t}{l}\right)=\sigma_{\mathrm{c}}
$$

It is noted here that no tension failure would occur in the pyramidal strut $(k=2)$ prior to the criterion given by Eq. A14 is satisfied when $t / l$ is no more than 0.53 (corresponding to $\bar{\rho}=0.24)$, i.e.,

$$
\sigma_{b}-\sigma_{A} \leq \sigma_{\mathrm{t}} \approx 580 \mathrm{MPa}
$$

where $\sigma_{\mathrm{t}}$ refers to tensile strength of the solid material (approximately equals to the flexural strength). Analytical analysis for higher $t / l$ ratios with $k=2$ end condition was not performed in the present study as strut aspect ratio at such high values becomes structurally impractical; furthermore, the FEM analysis indicated that the pyramidal strut end condition lies in between $k$ $=1$ and 2 . It should be noted here that the analysis for $k=2$ condition gives a conservative prediction as when compressive plastic yielding occurs on one side of the strut dangerous section, subsequent deformation behavior will deviate from linear elasticity and the strut can still support load until a plastic compressive stress distribution $\left(\sigma_{\mathrm{c}}\right)$ is achieved in that half dangerous section [51]. 


\section{References}

[1]Allen, H.G., Analysis and Design of Structural Sandwich Panels: The Commonwealth and International Library: Structures and Solid Body Mechanics Division. Elsevier, 2013.

[2] Deshpande, V. S., and Fleck, N. A., "Collapse of truss core sandwich beams in 3-point bending." International Journal of Solids and Structures 38, (2001): 6275-6305.

[3] Zok, F. W., Rathbun, H. J., Wei, Z., and Evans, A. G., "Design of metallic textile core sandwich panels." International Journal of Solids and Structures 40, (2003): 5707-5722.

[4] Deshpande, V. S., Fleck, N.A., and Ashby, M. F., "Effective properties of the octet-truss lattice material." Journal of the Mechanics and Physics of Solids 49, (2001): 1747-1769.

[5] Kooistra, G.W., Deshpande V. S., and Wadley H.N.G., "Compressive behavior of age hardenable tetrahedral lattice truss structures made from aluminium." Acta Materialia 52, (2004): 4229-4237.

[6] Kooistra, G. W., and Wadley, H. N.G., "Lattice truss structures from expanded metal sheet." Materials \& design 28, (2007): 507-514.

[7] Li, Q., Chen E.Y., Bice, D. R., and Dunand, D. C., "Mechanical properties of cast Ti-6Al-4V lattice block structures." Metallurgical and Materials Transactions A 39, (2008): 441-449.

[8] Queheillalt, D. T., and Wadley, H.N.G., "Titanium alloy lattice truss structures." Materials \& Design 30, (2009): 1966-1975.

[9] Dong, L., Deshpande, V.S., and Wadley, H.N.G., "Mechanical response of Ti-6Al-4V octet-truss lattice structures." International Journal of Solids and Structures 60, (2015): 107-124.

[10] Finnegan, K. A., "Carbon fiber composite pyramidal lattice structures." PhD diss., University of Virginia, 2007.

[11] Finnegan, K. A., Kooistra, G.W., Wadley, H.N.G, and Deshpande, V. S., "The compressive response of carbon fiber composite pyramidal truss sandwich cores." International Journal of Materials Research 98, (2007): 1264-1272.

[12] Russell, B., Deshpande, V.S., and Wadley, H.N.G., "Quasistatic deformation and failure modes of composite square honeycombs." Journal of mechanics of materials and structures 3, (2008): 1315-1340.

[13] Dong, L., and Wadley, H.N.G., "Mechanical properties of carbon fiber composite octet-truss lattice structures." Composites Science and Technology 119, (2015): 26-33.

[14] Dong, L., and Wadley, H.N.G., "Shear response of carbon fiber composite octet-truss lattice structures." Composites Part A: Applied Science and Manufacturing 81, (2016): 182-192.

[15] Wadley, H.N.G., Dharmasena, K. P., Queheillalt, D., Chen, Y., Dudt, P., Knight, D., Kiddy, K., Xue, Z., and Vaziri, A., "Dynamic compression of square honeycomb structures during underwater impulsive loading." Journal of mechanics of materials and structures 2, (2007): 2025-2048. 
[16] Dharmasena, K. P., Wadley, H.N.G., Xue, Z., and Hutchinson, J. W., "Mechanical response of metallic honeycomb sandwich panel structures to high-intensity dynamic loading." International Journal of Impact Engineering 35, (2008): 1063-1074.

[17] Wadley, H.N.G, Dharmasena, K. P., Chen, Y., Dudt, P., Knight, D., Charette, R., and Kiddy, K., "Compressive response of multilayered pyramidal lattices during underwater shock loading." International Journal of Impact Engineering 35, (2008): 1102-1114.

[18] Dharmasena, K. P., Queheillalt, D.T., Wadley, H. N.G, Chen, Y., Dudt, P., Knight, D., Wei, Z., and Evans, A.G., "Dynamic response of a multilayer prismatic structure to impulsive loads incident from water." International Journal of Impact Engineering 36, (2009): 632-643.

[19] Dharmasena, K. P., Wadley, H.N.G, Williams, K., Xue, Z., and Hutchinson, J. W., "Response of metallic pyramidal lattice core sandwich panels to high intensity impulsive loading in air." International Journal of Impact Engineering 38, (2011): 275-289.

[20] Yungwirth, C.J., O'Connor, J., Zakraysek, A., Deshpande, V.S. and Wadley, H.N.G., "Explorations of hybrid sandwich panel concepts for projectile impact mitigation." Journal of the American Ceramic Society, 94, (2011): S62-S75.

[21] Dharmasena, K. P., Wadley, H.N.G, Liu, T., and Deshpande V. S., "The dynamic response of edge clamped plates loaded by spherically expanding sand shells." International Journal of Impact Engineering 62, (2013): 182-195.

[22] Holloman, R. L., Deshpande, V.S., Hanssen, A., Fleming, K., Scully, J., and Wadley, H.N.G., "Tubular aluminum cellular structures: fabrication and mechanical response." Journal of Mechanics of Materials and Structures 8, (2013): 65-94.

[23] Wadley, H.N.G, Børvik, T., Olovsson, L., Wetzel, J.J., Dharmasena, K. P., Hopperstad, O.S., Deshpande, V. S., and Hutchinson, J. W., "Deformation and fracture of impulsively loaded sandwich panels." Journal of the Mechanics and Physics of Solids 61, (2013): 674-699.

[24] Holloman, R. L., Deshpande, V.S., and Wadley, H.N.G., "Impulse transfer during sand impact with a cellular structure." International Journal of Impact Engineering 82, (2015): 36-58.

[25] Wadley, H.N.G, Fleck, N. A., and Evans, A. G., "Fabrication and structural performance of periodic cellular metal sandwich structures." Composites Science and Technology 63, (2003): 2331-2343.

[26] Cote, F., Deshpande, V. S., Fleck, N. A., and Evans, A. G., "The out-of-plane compressive behavior of metallic honeycombs." Materials Science and Engineering: A 380, (2004): 272-280.

[27] Moongkhamklang, P., Deshpande, V.S., and Wadley, H.N.G., "The Compressive and Shear Response of Titanium Matrix Composite Lattice Structures”, Acta Materialia 58, (2010): 2822-2835.

[28] Zok, F. W., Waltner, S. A., Wei, Z., Rathbun, H. J., McMeeking, R. M., and Evans, A. G., "A protocol for characterizing the structural performance of metallic sandwich panels: application to pyramidal truss cores." International Journal of Solids and Structures 41, (2004): 6249-6271. 
[29] Gibson, L. J., and Ashby, M. F., Cellular solids: structure and properties. Cambridge university press, 1999.

[30] Nino, A., Tanaka, A., Sugiyama, S., and Taimatsu, H., "Indentation size effect for the hardness of refractory carbides." Materials transactions 51, (2010): 1621-1626.

[31] Munro, R. G., "Material properties of titanium diboride." Journal of Research of the National Institute of Standards and Technology 105, (2000): 709-720.

[32] Goetzel, C. G., Cermets, ASM Handbook, vol. 7. American Society for Metals, OH, 1993, 799-815.

[33] Keene, J.I., Agnew, S.R., Dong, L., Shamsujjoha, Md., O’Masta, M.R., and Wadley, H.N.G., "Microstructure characterization and chemical analysis of an impact resistant Ti(Mo)C-Ni cermet", In preparation.

[34] Keene, J.I., Agnew, S.R., Dong, L., and Wadley, H.N.G., "Characterization of a Ti(Mo)C-Ni Cermet Part II: Mechanical behavior", In preparation.

[35] Scheffler, M, and Colombo, P., eds. Cellular ceramics: structure, manufacturing, properties and applications. John Wiley \& Sons, 2006.

[36] Klaasen, H., Kollo, L. and Kübarsepp, J., "Mechanical properties and wear performance of compression sintered TiC-base cermets." Powder Metall., 50, (2007): 132-136.

[37] LaSalvia, J. C., and Meyers, M. A., "Microstructure, Properties, and Mechanisms of TiC-Mo-Ni Cermets produced by SHS," International Journal of Self-Propogating High-Temperature Synthesis, 4, (1995), 43-57.

[38] Compton, B. C. and Zok, F. W., "Impact resistance of TiC-based cermets," International Journal of Impact Engineering, 62, (2013): 75-87.

[39] Han, J., Zhang, X., and Wood, J. V., "In-situ combustion synthesis and densification of TiC-xNi cermets," Materials Science and Engineering A, 280, (2000): 328-333.

[40] Varma, A., Rogachev, A. S., Mukasyan, A. S., and Hwang, S., "Combustion synthesis of advanced materials: principles and applications." Advances in Chemical Engineering 24, (1998): 79-226.

[41] Cahn, R. W., "Self-propagating high-temperature synthesis." Advanced Materials 2, (1990): 314316.

[42] Subrahmanyam, J., and Vijayakumar, M., "Self-propagating high-temperature synthesis." Journal of Materials Science 27, (1992): 6249-6273.

[43] Heuer, A.H., Sears, J.S., Zaluzec, N.J., "Analytical Electron Microscopy of Phase Separated Ti/Mo Cemented Carbides and Carbonitrides," in Inst. Phys. Conf. Ser. No. 75: Ch. 4 Science of Hard Materials, (Adam Hilger Ltd.: 1986) pp. 321-334.

[44] Pang, J. H. L., Lead Free Solder: Mechanics and Reliability. Springer Science \& Business Media, 2011. 
[45] ABAQUS Analysis User's Manual, Version 6.12, P. Dassault Systèmes Simulia Corp., RI, USA, 2012.

[46] Moongkhamklang, P., and Wadley, H. N.G., "Titanium alloy lattice structures with millimeter scale cell sizes." Advanced Engineering Materials 12, (2010): 1111-1116.

[47] George, T., Deshpande, V. S., Sharp, K., and Wadley, H.N.G., "Hybrid core carbon fiber composite sandwich panels: Fabrication and mechanical response." Composite Structures 108, (2014): 696-710.

[48] Boresi, A. P., Schmidt R. J., and Sidebottom, O. M., Advanced mechanics of materials. Vol. 6. New York: Wiley, 1993.

[49] Xiong, J., Ma, L., Wu, L., Wang, B., and Vaziri, A., Fabrication and crushing behavior of low density carbon fiber composite pyramidal truss structures. Composite Structures 92, (2010), 2695-2702.

[50] Zhang, S., " Titanium carbonitride-based cermets: processes and properties." Materials Science and Engineering: A 163, (1993): 141-148.

[51] Shanley, F.R., Mechanics of Materials, McGraw-Hill, New York, 1967.

Figure 1. Material property charts showing (a) the compressive modulus and (b) the compressive strength experimental data and model predictions for the snap-fit $\mathrm{Ni}$ bonded $\mathrm{TiC}$ cermet pyramidal lattices investigated here.

Figure 2. (a) $\mu$-XCT image of the post-treated (HIP + stress relief) $\mathrm{Ni}$ bonded TiC cermet material used for the lattice structure fabrication. The sampled region is a cube with a side length of $1.3 \mathrm{~mm}$. (b) The 3D porosity distribution highlighted in blue. The samples average pore volume fraction was $1.4 \%$.

Figure 3. Scanning electron microscope image of the post-treated (HIP + stress relieved) $\mathrm{Ni}$ bonded TiC composite material used to fabricate the pyramidal lattices. Note the high number of particle-particle contacts.

Figure 4. Representative compressive stress versus strain response of the post-treated $(\mathrm{HIP}+$ stress relief) Ni bonded TiC composite.

Figure 5. Fabrication of a Ni bonded $\mathrm{TiC}$ pyramidal lattice unit cell structure. (a) Truss cutting by wire EDM; (b) the geometry of pyramidal truss rows with relevant core design variables identified; (c) assembled pyramidal unit cell structure; (d) vacuum braze joining of trusses and face sheets.

Figure 6. Photographs of the fabricated Ni bonded TiC composite pyramidal unit cells of various relative densities. 
Figure 7. SEM image (in BSE contrast mode) of a braze joint (a) and the corresponding elemental composition maps (b)-(f).

Figure 8. Compressive stress-strain responses of the pyramidal lattice structures. The dashed curves correspond to FEM results obtained using $\sigma_{c}=2600$ and $3300 \mathrm{MPa}$ material models (for the lower and upper bound FEM predictions).

Figure 9. High-speed video image sequences showing the oblique view of a $\bar{\rho}=8.2 \%$ pyramidal unit cell sample. $t_{0}$ and $t_{1}$ refer to the time points shown in Figure 8.

Figure 10. Schematic illustrations showing the failure mechanism of a pyramidal truss in two and three dimensional perspectives.

Figure 11. Representative fracture surface images showing (a) truss failure surface and (b) node region after compression failure of a pyramidal lattice.

Figure 12. DIC measured von Mises strain just prior to attainment of the peak stress for a $\bar{\rho}=$ $8.2 \%$ pyramidal unit cell sample.

Figure 13 (a) Photography of pyramidal trusses used for assembling a multi-cell $(2 \times 3)$ pyramidal lattice $(\bar{\rho}=8.2 \%)$ sandwich panel. (b) Top view of the assembled pyramidal lattice $(\bar{\rho}=8.2 \%$ ) with top face sheet removed. (c) Photography of the corresponding pyramidal lattice after brazing.

Figure 14. (a) Comparison of unit cell and multi-cell pyramidal lattices $(\bar{\rho}=8.2 \%)$ mechanical responses together with FEM predictions. (b) A high-speed video image sequences of the multicell pyramidal lattice during compression failure.

Figure 15. Finite element analysis showing von Mises stress distribution in the $\bar{\rho}=8.2 \%$ pyramidal lattice at different strains. Regions with gray color represent the regions where initial fracture failure occurred. Materials model with $\sigma_{c}=2600 \mathrm{MPa}$ was used for the $\mathrm{FE}$ analysis.

Figure 16. Comparison between predictions and measurements for (a) compressive modulus and (b) compressive strength of pyramidal unit cell samples as a function of their relative density. A conservative compressive strength of $2600 \mathrm{MPa}$ was used for the analytical model predictions. Material models with $\sigma_{c}=2600$ and $3300 \mathrm{MPa}$ were used for the lower and upper bound FEM predictions. 
Table 1: Summary of mechanical properties of the Ni bonded TiC composite materials obtained by uniaxial compression and four points bending tests.

\begin{tabular}{lcc}
\hline \multicolumn{1}{c}{ Property } & Value & Standard deviation \\
\hline Elastic modulus (GPa) & 359 & 26.1 \\
Compressive strength (MPa) & 2778 & 187 \\
Flexural strength (MPa) & 579 & 79 \\
\hline
\end{tabular}

Table 2: Node and strut dimensions for the pyramidal lattices used in this study (unit: $\mathrm{mm}$ ).

\begin{tabular}{ccccccc}
\hline \hline$t$ & $w$ & $b$ & $c$ & $h$ & $h_{\text {tab }}$ & $\omega$ \\
\hline 1.588 & 1.588 & 4.763 & 2.235 & 0.953 & 1.588 & $45^{\circ}$ \\
\hline
\end{tabular}

Table 3: Dimensional parameters of the fabricated Ni bonded TiC composite unit cell pyramidal unit cell samples.

\begin{tabular}{cccc}
\hline \hline Length & $\begin{array}{c}\text { Relative } \\
\text { density }\end{array}$ & $\begin{array}{c}\text { Pyramidal lattice } \\
\text { side length }(\mathrm{mm})\end{array}$ & $\begin{array}{c}\text { Pyramidal lattice } \\
\text { height }(\mathrm{mm})\end{array}$ \\
\hline 26.08 & $1.5 \%$ & 31.029 & 19.397 \\
16.89 & $3.0 \%$ & 21.838 & 12.896 \\
11.94 & $5.1 \%$ & 16.888 & 9.395 \\
8.44 & $8.2 \%$ & 13.388 & 6.921 \\
5.08 & $14.9 \%$ & 10.028 & 4.545 \\
3.56 & $21.0 \%$ & 8.508 & 3.470 \\
\hline
\end{tabular}


Table 4: Relative densities, experimental compressive moduli and strengths of the snap-fit Ni bonded TiC composite unit cell pyramidal lattices. FEM predictions are provided for comparison using $\sigma_{c}=2600 \mathrm{MPa}$ and $\sigma_{c}=3300 \mathrm{MPa}$. Analytical model predictions assumed a conservative compressive strength $\sigma_{c}=2600 \mathrm{MPa}$.

\begin{tabular}{cccccccc}
\hline $\begin{array}{c}\text { Truss } \\
\text { length }\end{array}$ & $\begin{array}{c}\text { Relative } \\
\text { density }\end{array}$ & \multicolumn{4}{c}{ Compressive stiffness (GPa) } & \multicolumn{3}{c}{ Compressive strength (MPa) } \\
\cline { 3 - 8 }$(l, \mathrm{~mm})$ & $(\bar{\rho})$ & Experiment & FEM & $\begin{array}{c}\text { Analytical } \\
k=1 / k=2\end{array}$ & Experiment & $\begin{array}{c}\text { FEM } \\
(\mathrm{min} / \mathrm{max})\end{array}$ & $\begin{array}{c}\text { Analytical } \\
k=1 / k=2\end{array}$ \\
\hline 26.08 & $1.5 \%$ & 1.4 & 1.4 & $1.4 / 1.4$ & 10.4 & $13.3 / 13.3$ & $8.1 / 16.3$ \\
16.89 & $3.0 \%$ & 2.5 & 2.8 & $2.9 / 2.9$ & 36.7 & $32.2 / 38.4$ & $38.9 / 30.6$ \\
11.94 & $5.1 \%$ & 4.3 & 4.9 & $5.0 / 5.1$ & 60.6 & $52.4 / 69.1$ & $65.0 / 47.3$ \\
8.44 & $8.2 \%$ & 7.8 & 8.3 & $8.3 / 8.6$ & 88.8 & $78.6 / 107.2$ & $103.4 / 68.4$ \\
5.08 & $14.9 \%$ & 14.7 & 17.1 & $16.1 / 17.7$ & 184.3 & $130.9 / 181.2$ & $184.3 / 104.4$ \\
3.56 & $21.0 \%$ & 20.9 & 27.9 & $24.4 / 29.3$ & 247.2 & $179.3 / 244.8$ & $256.0 / 131.3$ \\
\hline
\end{tabular}

Table 5: Comparison of measured and FEM simulated mechanical properties of Ni bonded TiC composite pyramidal lattices with a relative density $\bar{\rho}=8.2 \%$. FEM predictions used with $\sigma_{c}=2600 \mathrm{MPa}$ for FEM (min) and $\sigma_{c}=3300 \mathrm{MPa}$ for FEM (max).

\begin{tabular}{cccccc}
\hline \multirow{2}{*}{ Type } & Relative & \multicolumn{2}{c}{ Compressive stiffness (GPa) } & \multicolumn{2}{c}{ Compressive strength (MPa) } \\
\cline { 3 - 5 } & density $(\bar{\rho})$ & Experiment & FEM & Experiment & FEM (min/max) \\
\hline Unit cell & $8.2 \%$ & 7.8 & 8.3 & 88.8 & $78.6 / 107.2$ \\
Multi-cell & $8.2 \%$ & 7.9 & 8.3 & 98.5 & $78.6 / 107.2$ \\
\hline
\end{tabular}




\section{Appendix:}

Figure A1. (a) View of a pyramidal unit cell subjected to $z$ direction compression loading. (b) Free-body diagram of a strut (highlighted in (a)) loaded in a combination of compression and shear. 

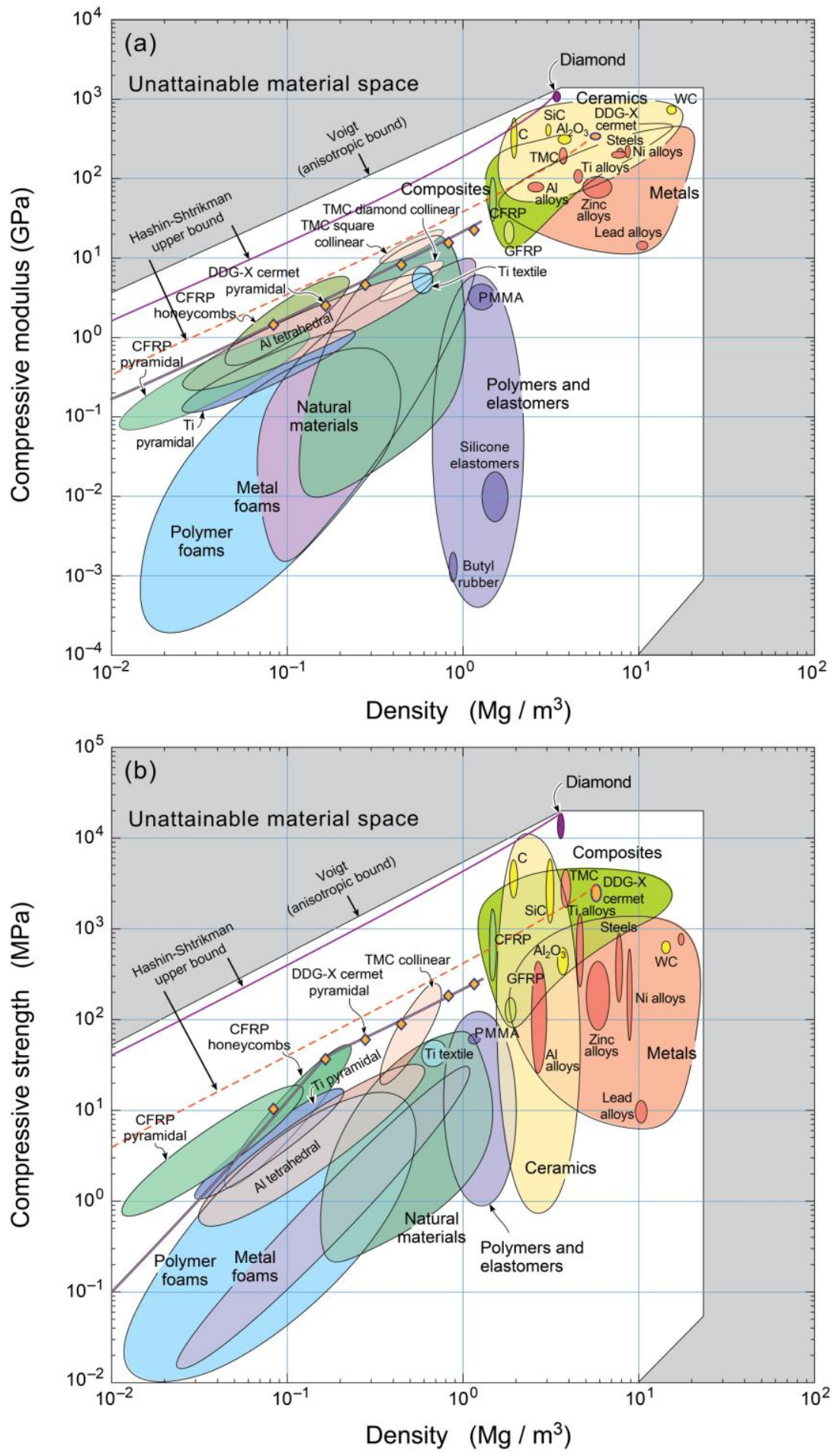

Figure 1. Material property charts showing (a) the compressive modulus and (b) the compressive strength experimental data and model predictions for the snap-fit $\mathrm{Ni}$ bonded $\mathrm{TiC}$ cermet pyramidal lattices investigated here. 

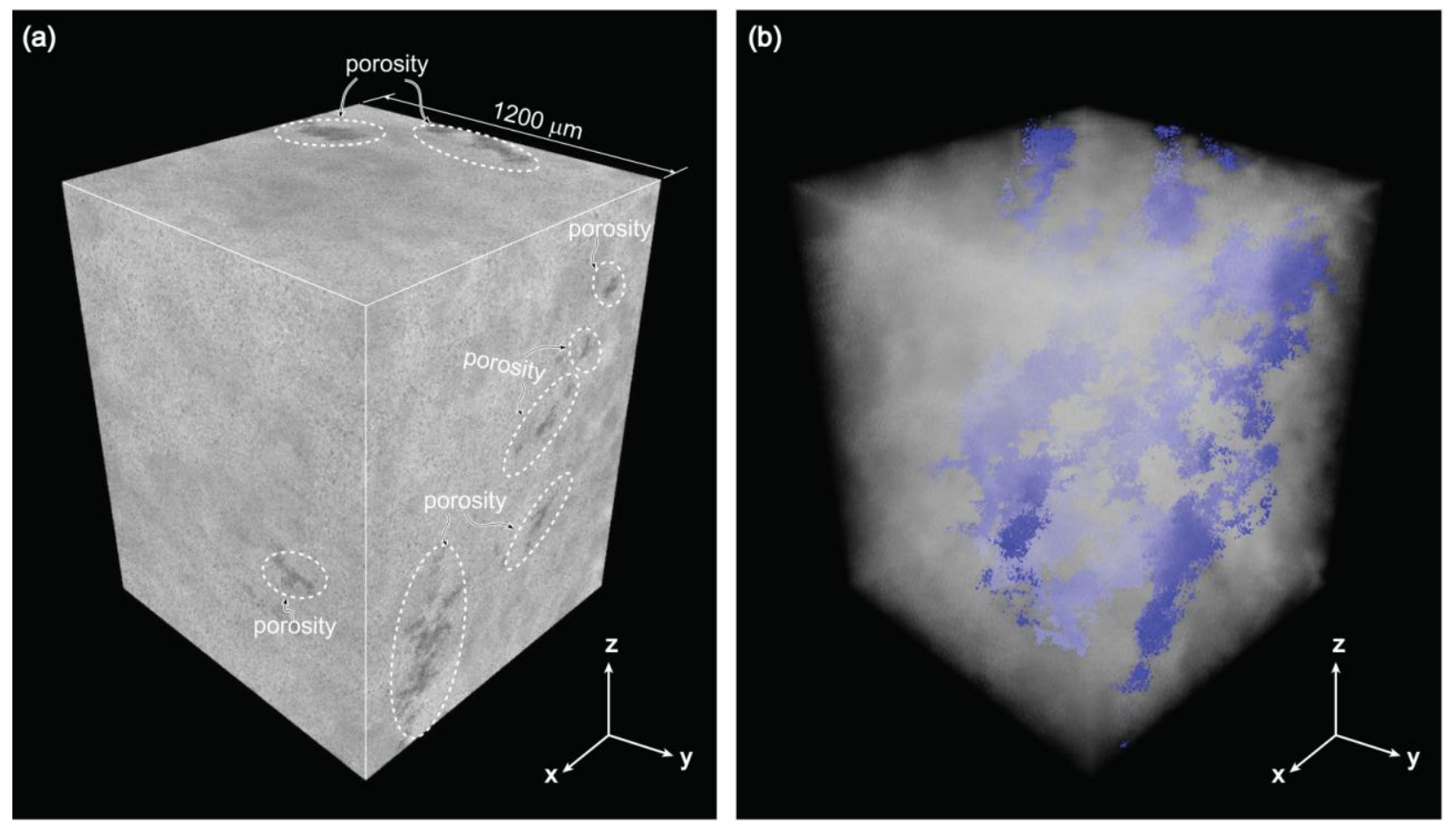

Figure 2. (a) $\mu$-XCT image of the post-treated (HIP + stress relief) $\mathrm{Ni}$ bonded TiC cermet material used for the lattice structure fabrication; (b) porosity distribution in 3D view and highlighted in blue. The samples average pore volume fraction was about $1.4 \%$. 


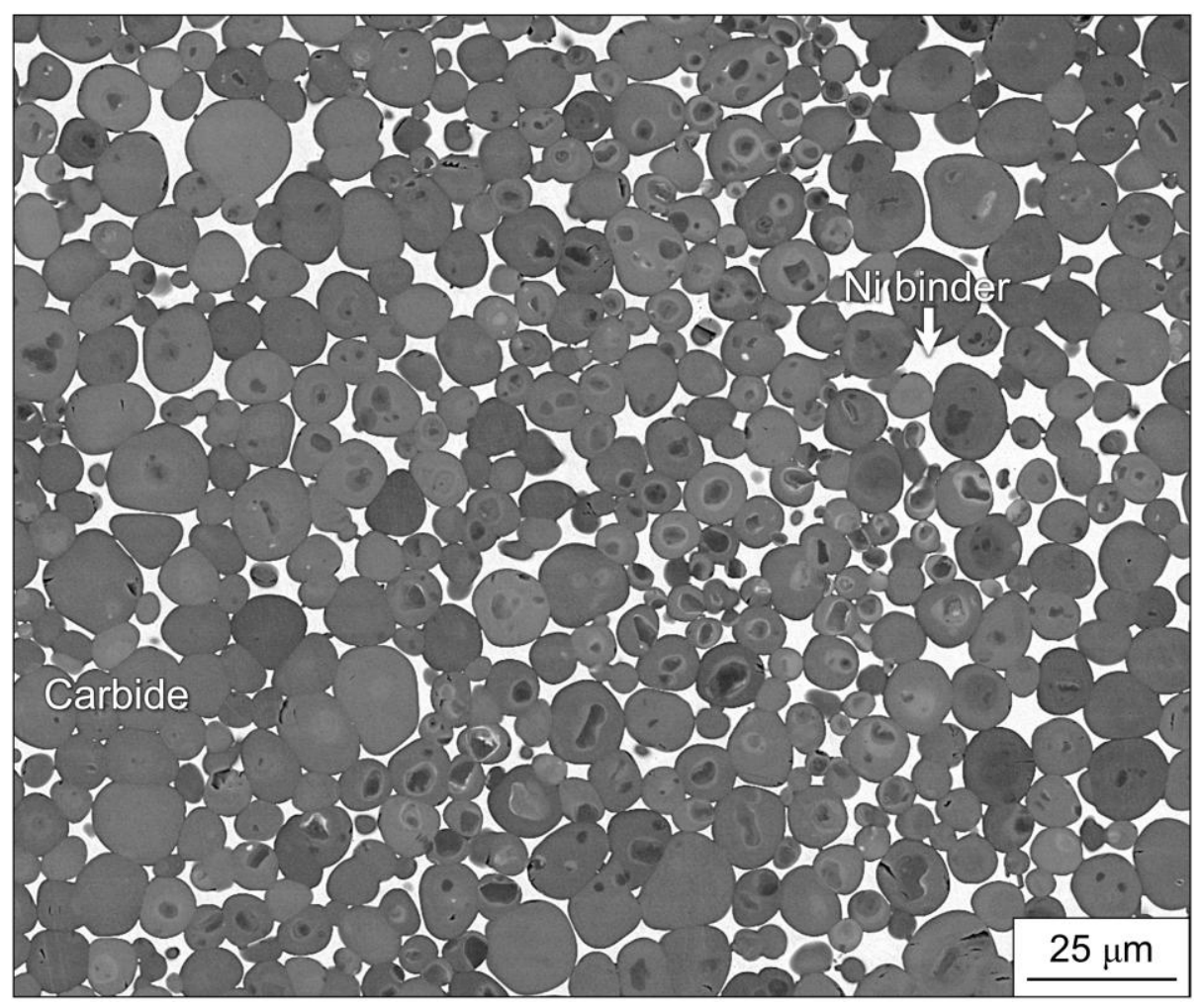

Figure 3. Scanning electron microscope image of the post-treated (HIP + stress relieved) $\mathrm{Ni}$ bonded $\mathrm{TiC}$ composite material used to fabricate the pyramidal lattices. 


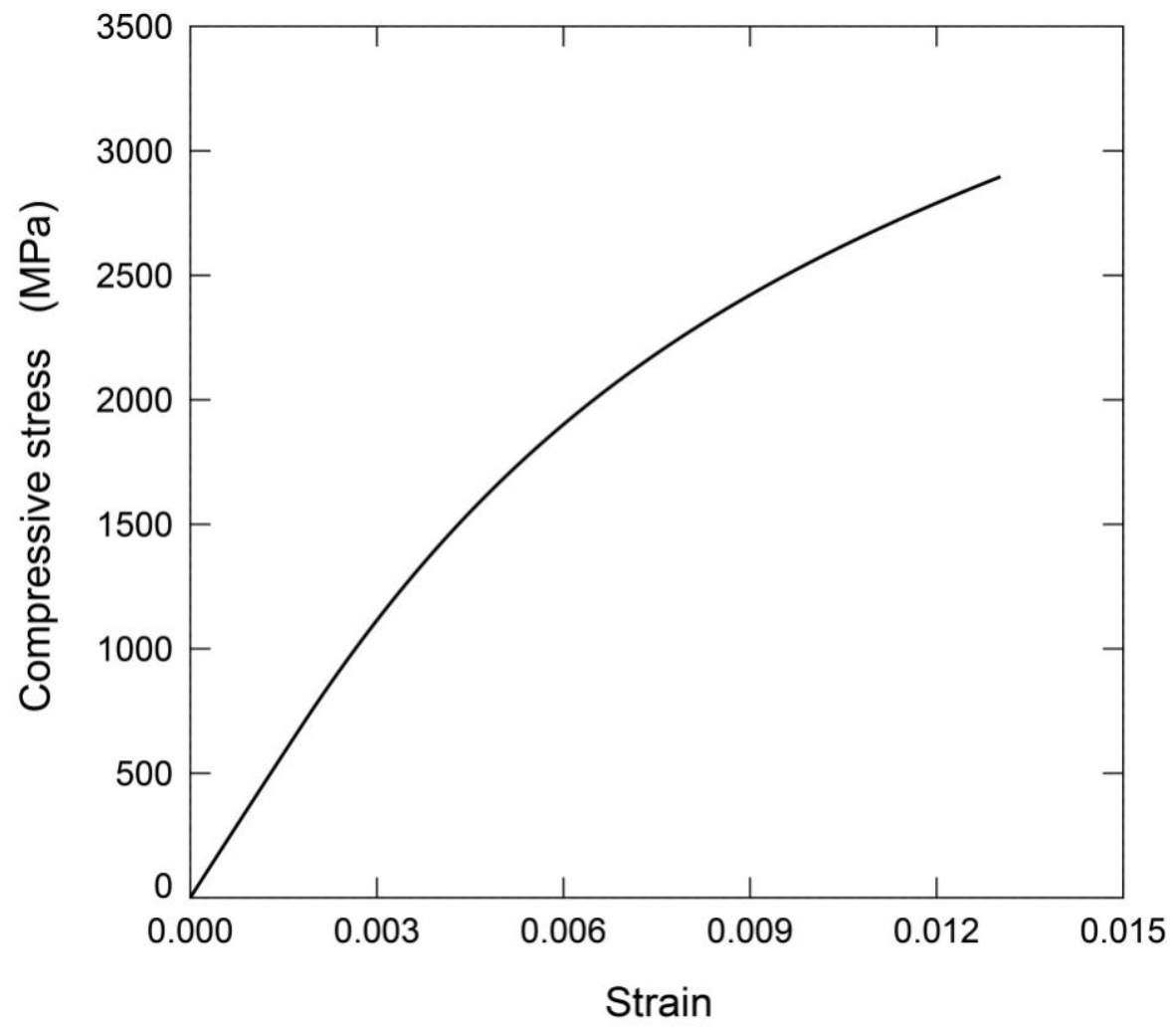

Figure 4. Representative compressive stress versus strain response of the post-treated (HIP + stress relief) Ni bonded TiC composite. 

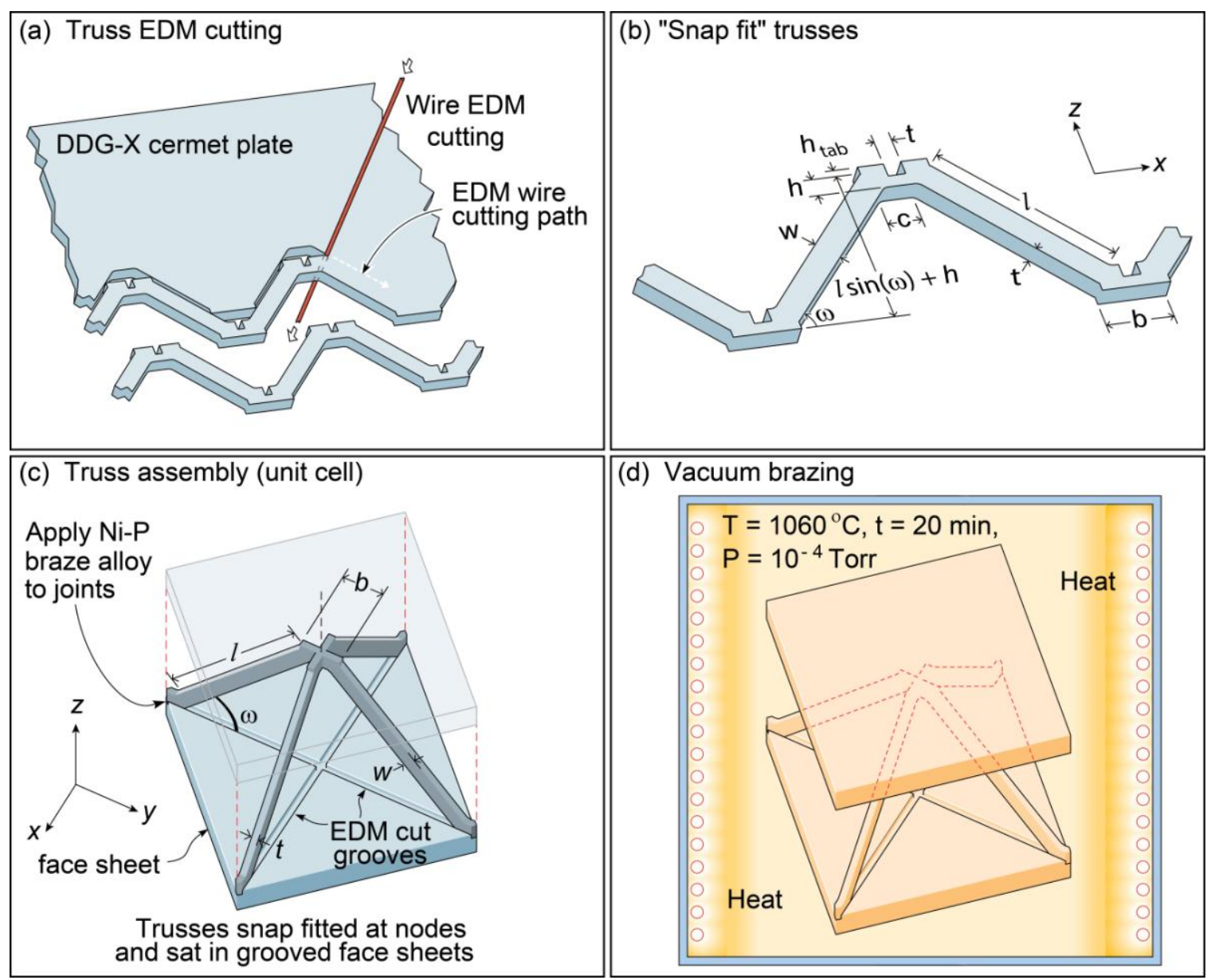

Figure 5. Fabrication of a $\mathrm{Ni}$ bonded $\mathrm{TiC}$ pyramidal lattice unit cell structure. (a) Truss cutting by wire EDM; (b) the geometry of pyramidal truss rows with relevant core design variables identified; (c) assembled pyramidal unit cell structure; (d) vacuum braze joining of trusses and face sheets. 


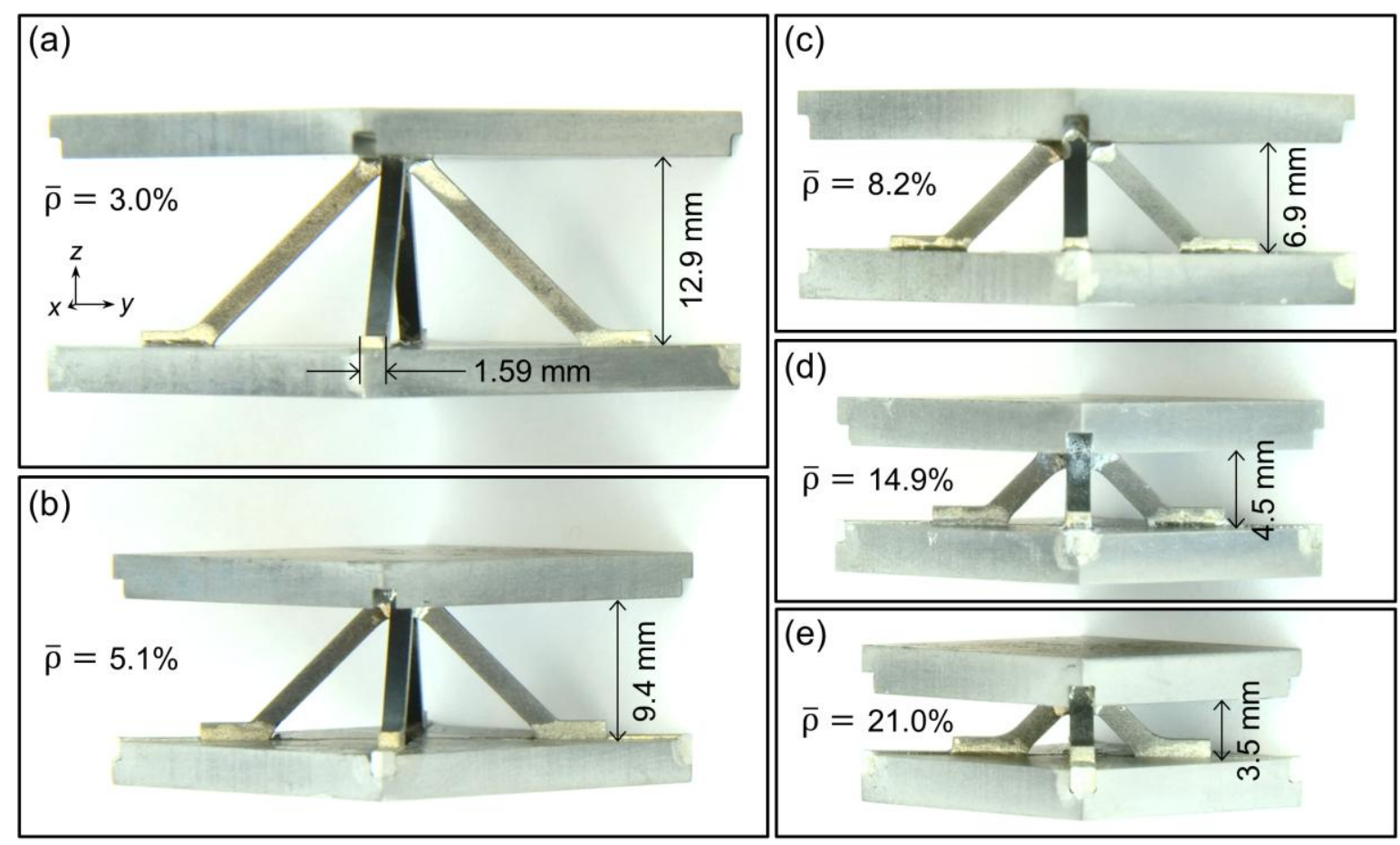

Figure 6. Photographs of the fabricated Ni bonded TiC composite pyramidal unit cells of various relative densities. 

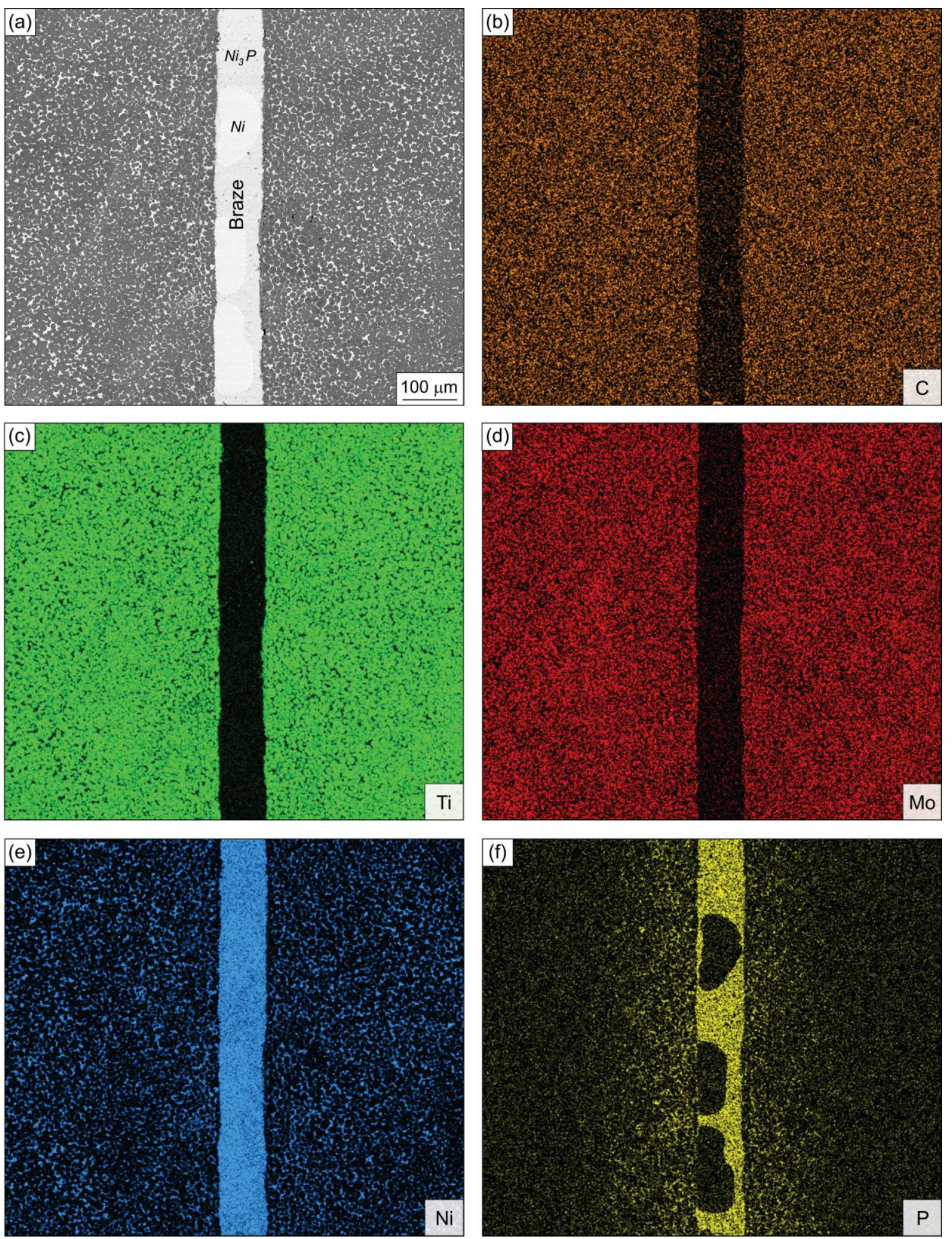

Figure 7. Microstructure image (in BSE contrast mode) of a braze joint (a) and the corresponding elemental composition maps (b)-(f). 


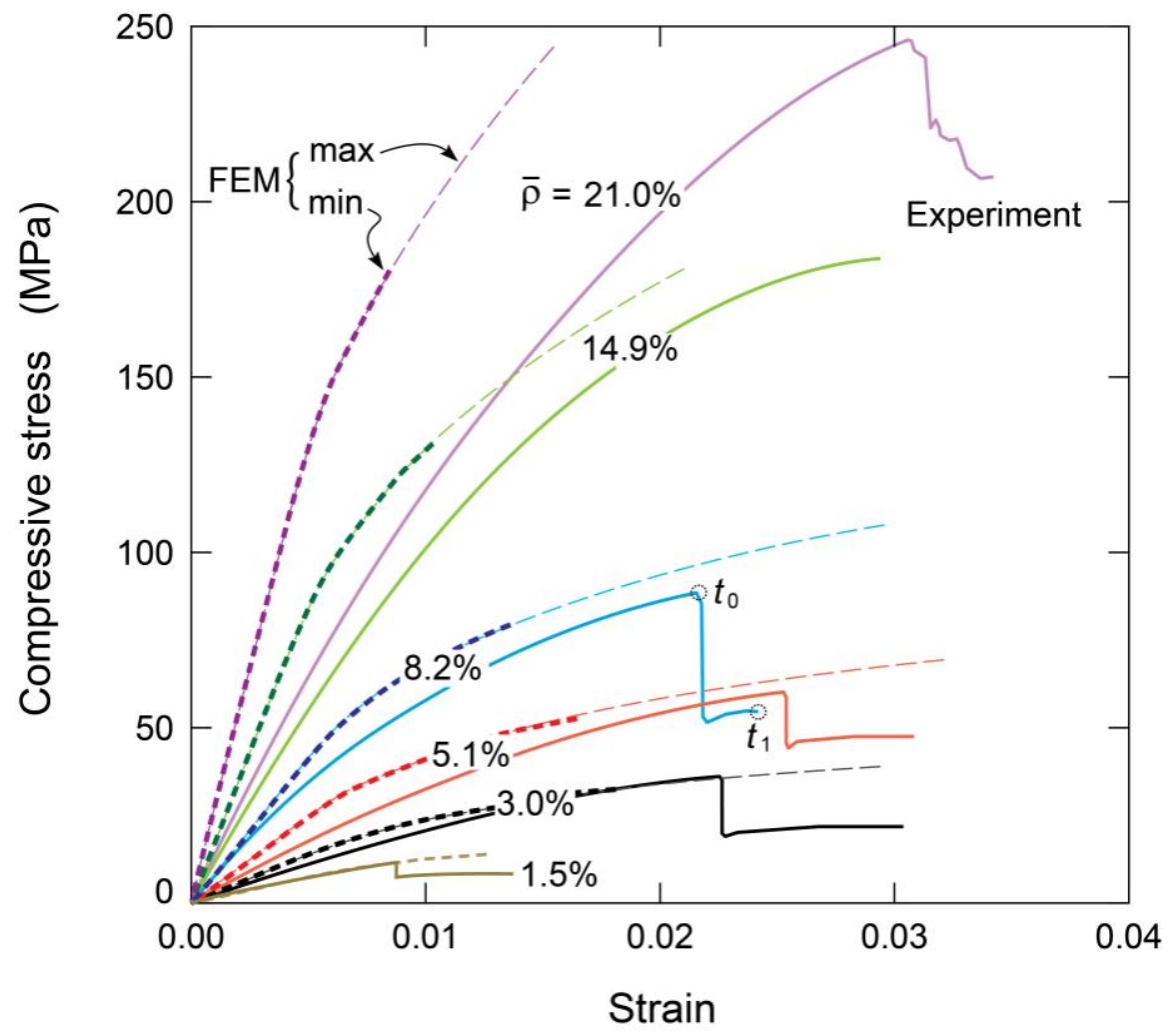

Figure 8. Compressive stress-strain responses of the pyramidal lattice structures. The dashed curves correspond to FEM results obtained using $\sigma_{c}=2600$ and $3300 \mathrm{MPa}$ material models (for the minimum and maximum FE predictions). 

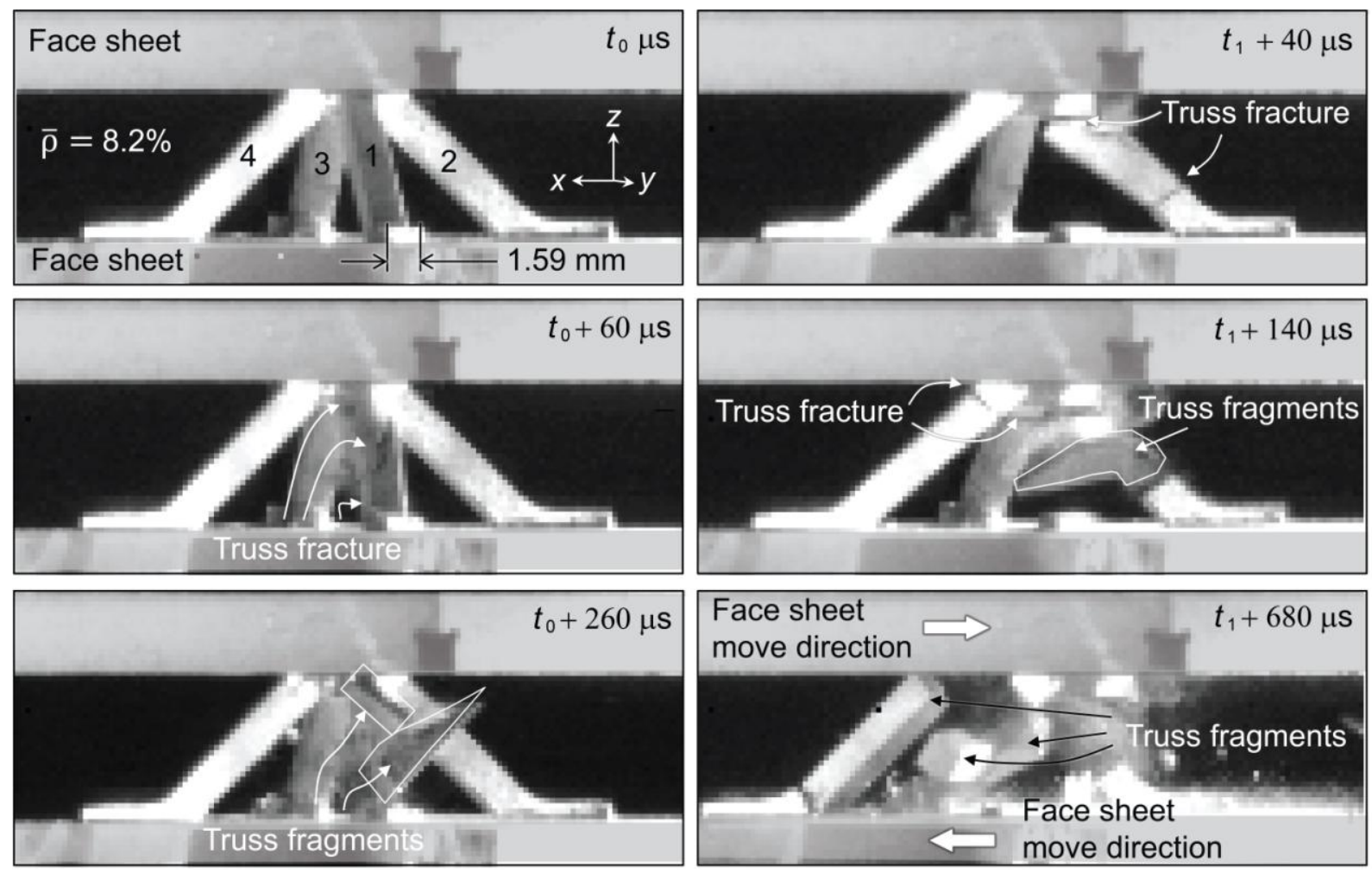

Figure 9. High-speed video image sequences showing the oblique view of a $\bar{\rho}=8.2 \%$ pyramidal unit cell sample. $t_{0}$ and $t_{1}$ refer to the time points shown in Figure 7. 

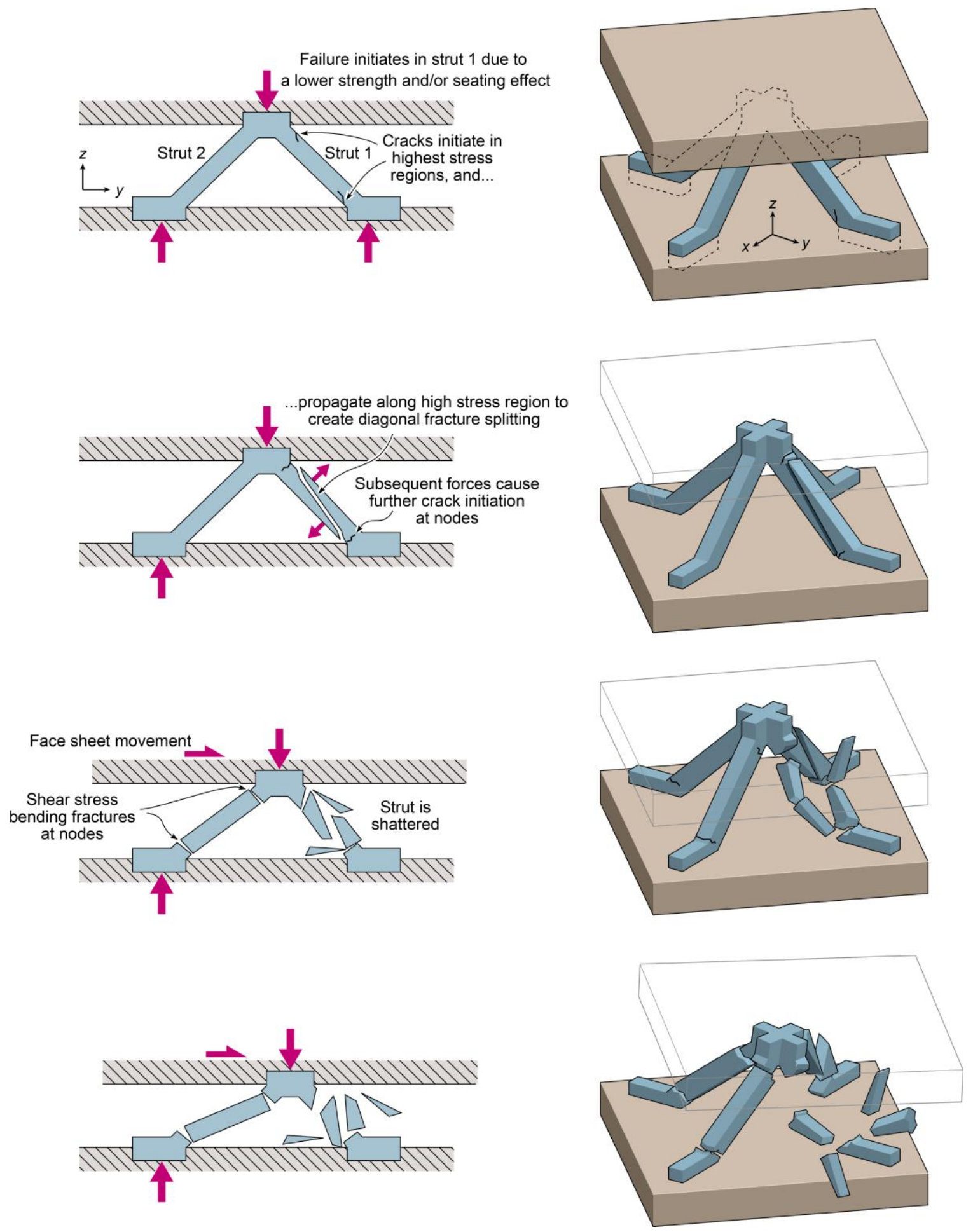

Figure 10. Schematic drawing of the failure mechanism of a pyramidal truss in $2 \mathrm{D}$ and $3 \mathrm{D}$ perspective. 

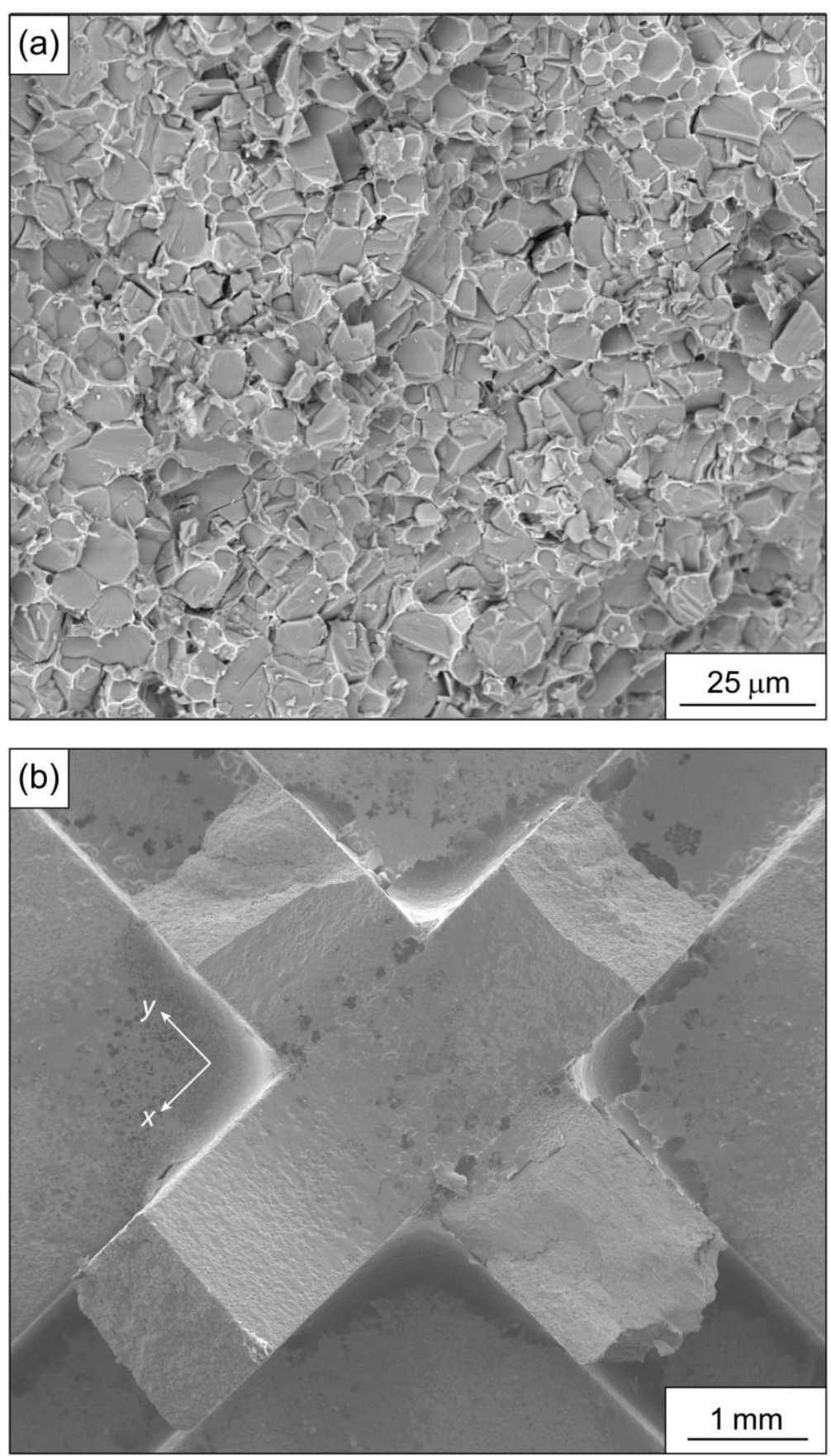

Figure 11. Representative fracture surface images showing (a) truss failure surface and (b) node region after compression failure of a pyramidal lattice. 


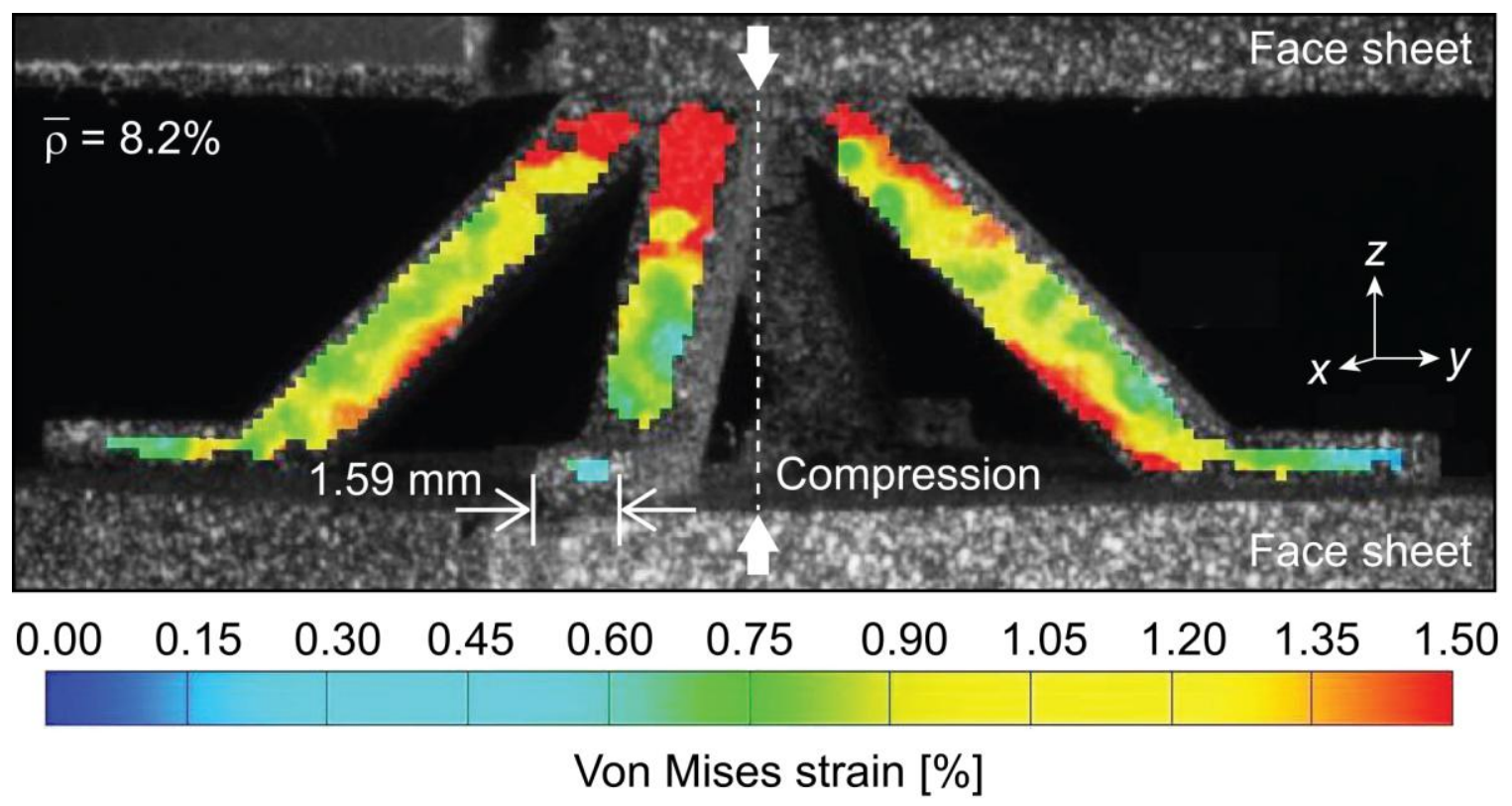

Figure 12. DIC measured von Mises strain just prior to attainment of the peak stress for a $\bar{\rho}=$ $8.2 \%$ pyramidal unit cell sample. 

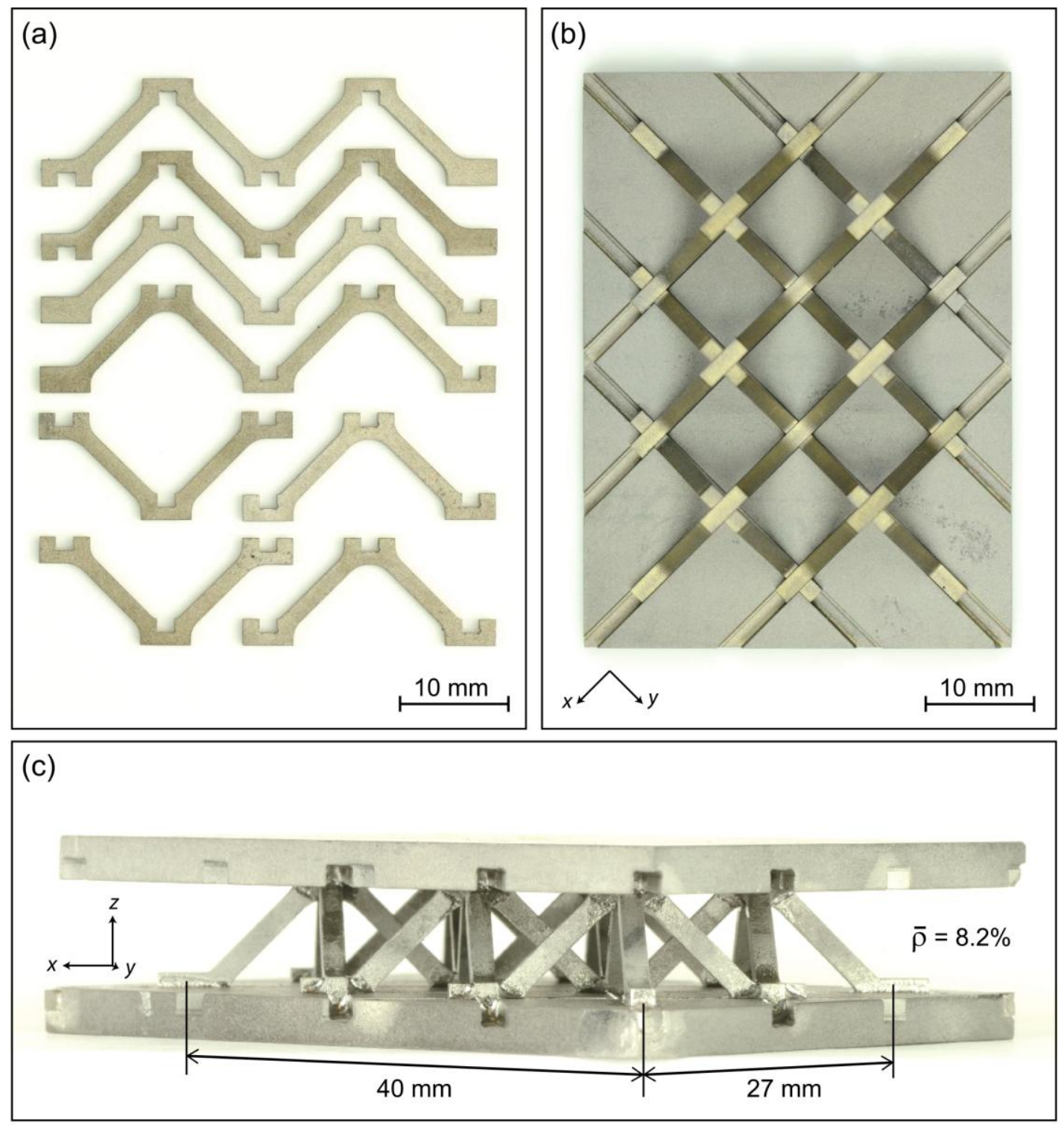

Figure 13 (a) Photography of pyramidal trusses used for assembling a multi-cell $(2 \times 3)$ pyramidal lattice $(\bar{\rho}=8.2 \%)$ sandwich panel. (b) Top view of the assembled pyramidal lattice $(\bar{\rho}=8.2 \%$ ) with top face sheet removed. (c) Photography of the corresponding pyramidal lattice after brazing. 


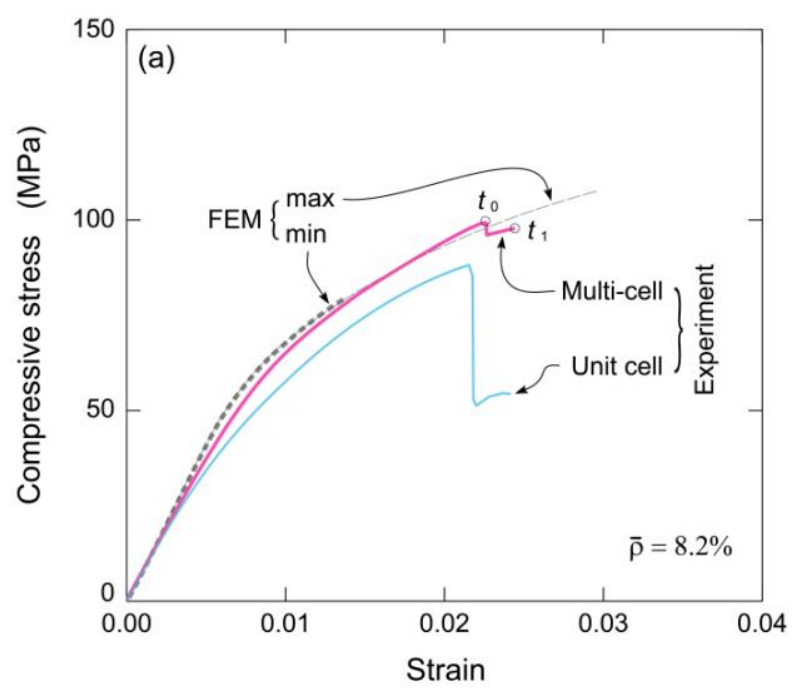

(b)
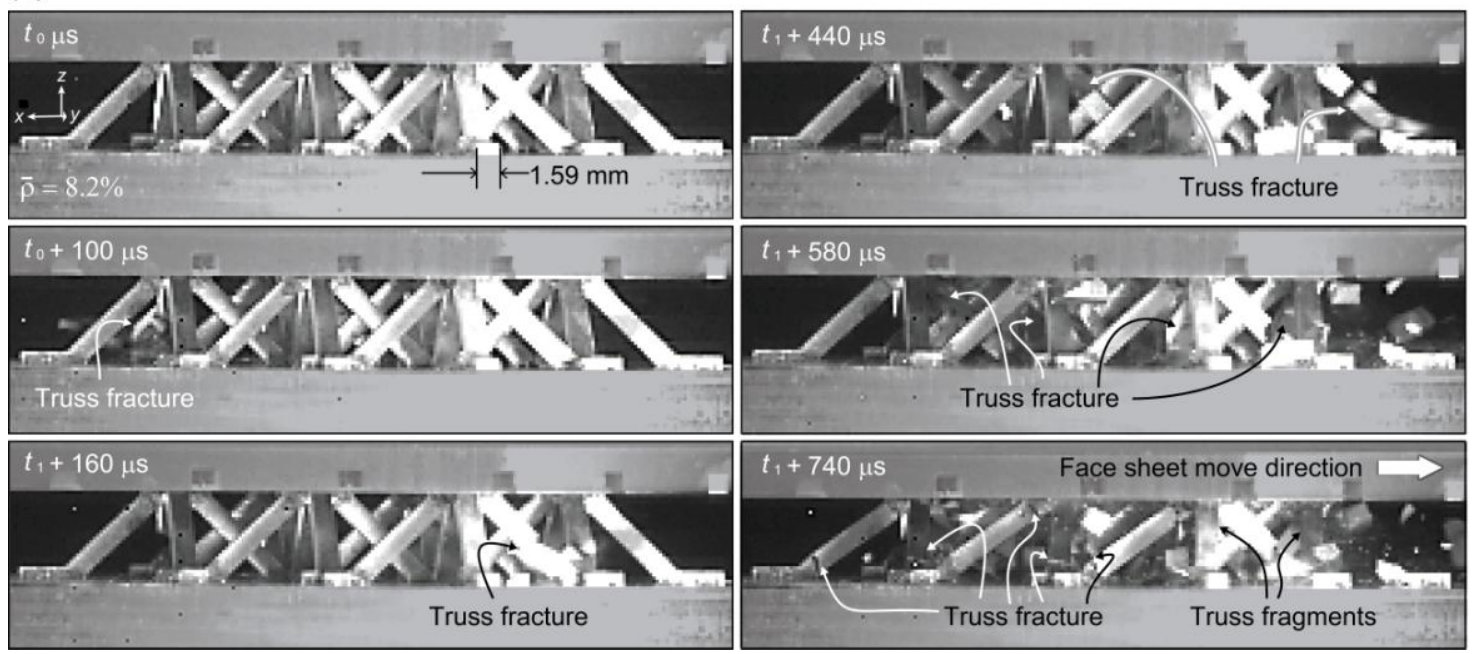

Figure 14. (a) Comparison of unit cell and multi-cell pyramidal lattices $(\bar{\rho}=8.2 \%)$ mechanical responses together with FEM predictions. (b) A high-speed video image sequences of the multicell pyramidal lattice during compression failure. 

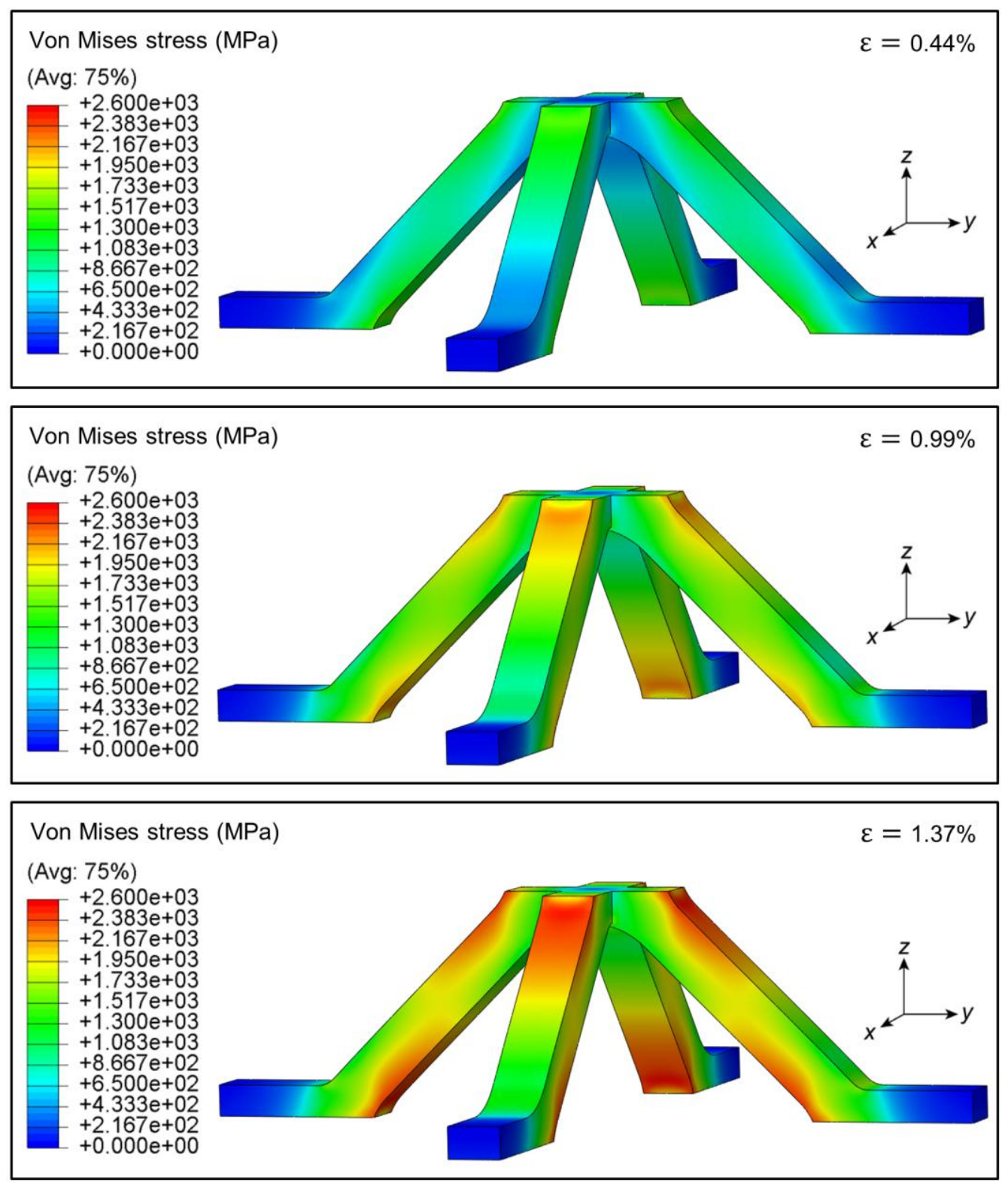

Figure 15. Finite element analysis showing von Mises stress distribution in the $\bar{\rho}=8.2 \%$ pyramidal lattice at different strains. Regions with gray color represent the regions where initial fracture failure occurred. Materials model with $\sigma_{c}=2600 \mathrm{MPa}$ was used for the FE analysis. 

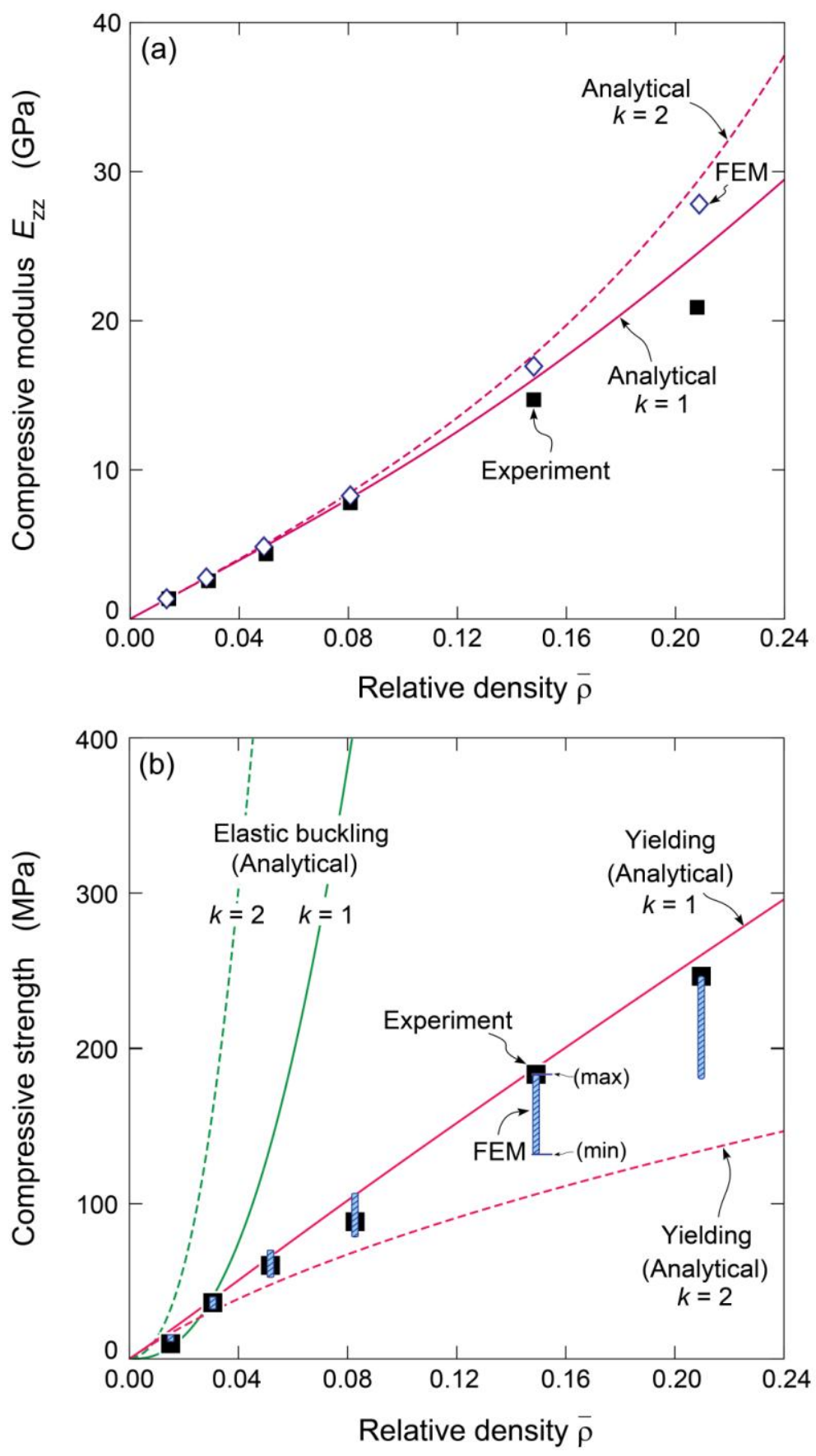

Figure 16. Comparison between predictions and measurements for (a) compressive modulus and (b) compressive strength of pyramidal unit cell samples as a function of their relative density. A conservative compressive strength of $2600 \mathrm{MPa}$ was used for the analytical model predictions. Material models with $\sigma_{c}=2600$ and $3300 \mathrm{MPa}$ were used for the minimum and maximum FEM predictions. 

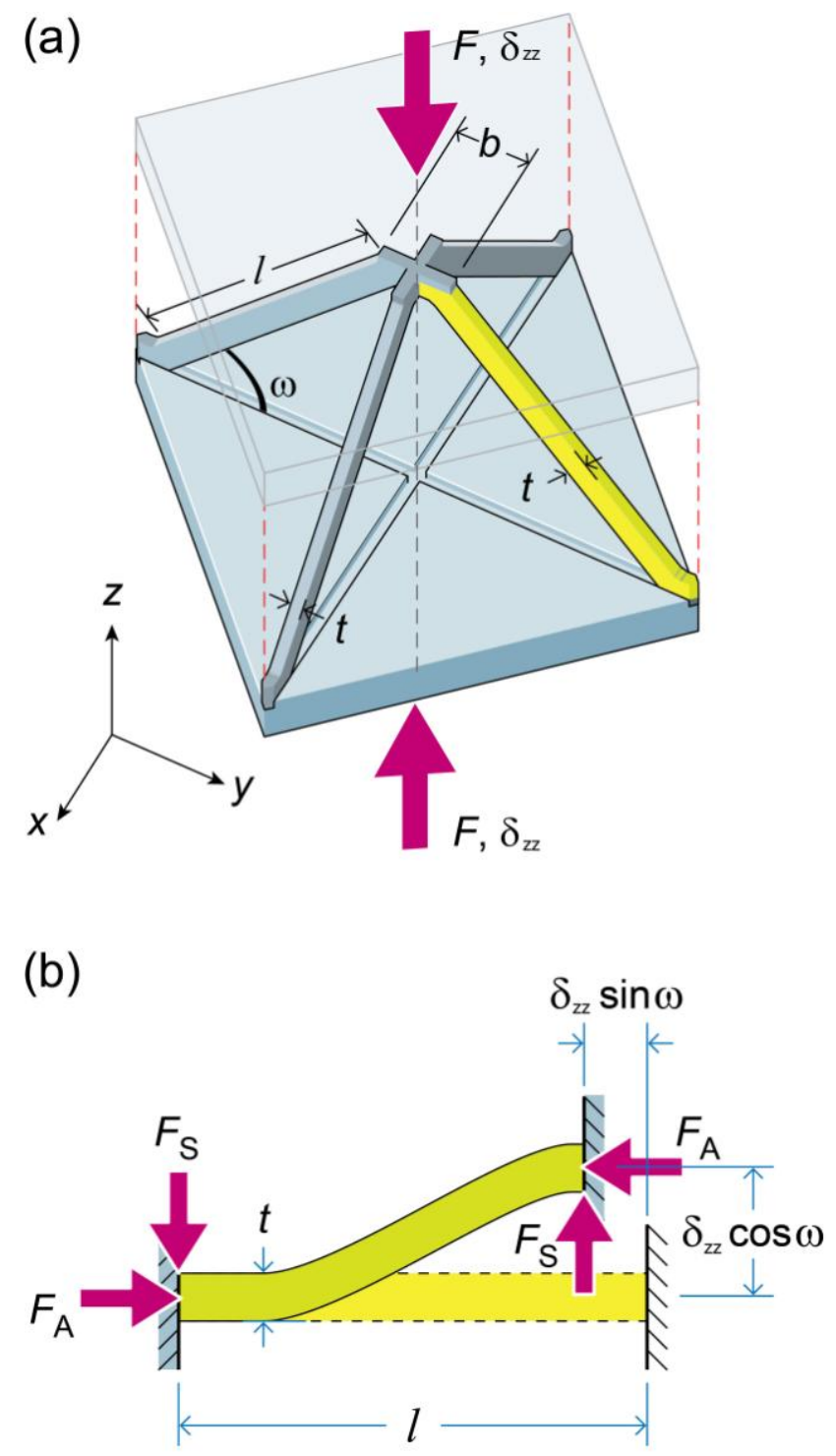

Figure A1. (a) View of a pyramidal unit cell subjected to $z$ direction compression loading. (b) Free-body diagram of a strut (highlighted in (a)) loaded in a combination of compression and shear. 